Article

\title{
Cupriavidus metallidurans Strains with Different Mobilomes and from Distinct Environments Have Comparable Phenomes
}

\author{
Rob Van Houdt ${ }^{1, *(1)}$, Ann Provoost ${ }^{1}$, Ado Van Assche ${ }^{2}$, Natalie Leys ${ }^{1} \mathbb{1}$, Bart Lievens ${ }^{2}$, \\ Kristel Mijnendonckx ${ }^{1}$ (D) and Pieter Monsieurs ${ }^{1}$ \\ 1 Microbiology Unit, Belgian Nuclear Research Centre (SCK•CEN), B-2400 Mol, Belgium; \\ aprovoos@sckcen.be (A.P.); nleys@sckcen.be (N.L.); kmijnend@sckcen.be (K.M.); pmonsieu@sckcen.be (P.M.) \\ 2 Laboratory for Process Microbial Ecology and Bioinspirational Management, KU Leuven, \\ B-2860 Sint-Katelijne-Waver, Belgium; ado.vanassche@kuleuven.be (A.V.A.); \\ bart.lievens@kuleuven.be (B.L.) \\ * Correspondence: rvhoudto@sckcen.be
}

Received: 21 September 2018; Accepted: 15 October 2018; Published: 18 October 2018

\begin{abstract}
Cupriavidus metallidurans has been mostly studied because of its resistance to numerous heavy metals and is increasingly being recovered from other environments not typified by metal contamination. They host a large and diverse mobile gene pool, next to their native megaplasmids. Here, we used comparative genomics and global metabolic comparison to assess the impact of the mobilome on growth capabilities, nutrient utilization, and sensitivity to chemicals of type strain CH34 and three isolates (NA1, NA4 and H1130). The latter were isolated from water sources aboard the International Space Station (NA1 and NA4) and from an invasive human infection (H1130). The mobilome was expanded as prophages were predicted in NA4 and H1130, and a genomic island putatively involved in abietane diterpenoids metabolism was identified in H1130. An active CRISPR-Cas system was identified in strain NA4, providing immunity to a plasmid that integrated in CH34 and NA1. No correlation between the mobilome and isolation environment was found. In addition, our comparison indicated that the metal resistance determinants and properties are conserved among these strains and thus maintained in these environments. Furthermore, all strains were highly resistant to a wide variety of chemicals, much broader than metals. Only minor differences were observed in the phenomes (measured by phenotype microarrays), despite the large difference in mobilomes and the variable (shared by two or three strains) and strain-specific genomes.
\end{abstract}

Keywords: phenotype microarray; mobile genetic elements; Cupriavidus; metal; resistance

\section{Introduction}

Cupriavidus metallidurans type strain $\mathrm{CH} 34$, which was isolated from a decantation basin in the non-ferrous metallurgical factory at Engis, Belgium [1], has been mostly studied because of its resistance to numerous heavy metals [2]. It tolerates high concentrations of metal (oxyan)ions, including $\mathrm{Cu}^{+}$, $\mathrm{Cu}^{2+}, \mathrm{Ni}^{2+}, \mathrm{Zn}^{2+}, \mathrm{Co}^{2+}, \mathrm{Cd}^{2+}, \mathrm{CrO}_{4}{ }^{2-}, \mathrm{Pb}^{2+}, \mathrm{Ag}^{+}, \mathrm{Au}^{+}, \mathrm{Au}^{3+}, \mathrm{HAsO}_{4}{ }^{2-}, \mathrm{AsO}^{2-}, \mathrm{Hg}^{2+}, \mathrm{Cs}^{+}, \mathrm{Bi}^{3+}, \mathrm{Tl}^{+}$, $\mathrm{SeO}_{3}{ }^{2-}, \mathrm{SeO}_{4}{ }^{2-}$ and $\mathrm{Sr}^{2+}$ [2,3]. Metal detoxification is encoded by at least 24 gene clusters and many of them are carried by its two megaplasmids pMOL28 and pMOL30 [4]. Resistance to metal ions is mediated by multiple systems, including transporters belonging to the resistance nodulation cell division (RND), the cation diffusion facilitator (CDF) and the P-type ATPase families $[2,5]$.

Cupriavidus metallidurans strains have characteristically been isolated from metal-contaminated industrial environments such as soils around metallurgical factories in the Congo (Katanga) and North-Eastern Belgium [6,7], as well as from contaminated soils in Japan [8] and gold mining sites in 
Queensland (Australia) [9]. Other environments include sewage plants [10], laboratory wastewater (Okayama University, Okayama, Japan) [11] and spacecraft assembly cleanrooms [12]. In addition, C. metallidurans strains were also found in the drinking water and dust collected from the International Space Station (ISS) [12,13].

Remarkably, more and more reports describe the isolation of $C$. metallidurans strains from medically-relevant settings and sources such as the pharmaceutical industry, human cerebrospinal fluid and cystic fibrosis patients [14]. It remains to be elucidated if the isolates caused the active infection or only intruded as secondary opportunistic pathogens [14]. Nevertheless, an invasive human infection and four cases of catheter-related infections caused by $C$. metallidurans were recently reported $[15,16]$.

All Cupriavidus genomes characteristically carry, next to their chromosome, a second large replicon. This 2 to $3 \mathrm{Mb}$-sized replicon has recently been coined chromid as it neither fully fits the term chromosome nor plasmid [17,18]. In addition to the chromid, most Cupriavidus strains harbor one or more megaplasmids (100 kb or larger in size), which probably mediate the adaptation to certain ecological niches by the particular functions they encode (see [19] for detailed review). For instance, pMOL28 and pMOL30 from C. metallidurans $\mathrm{CH} 34$ are pivotal in metal ion resistance [4]; hydrogenotrophic and chemolithotrophic metabolism are encoded by pHG1 from Cupriavidus necator H16 [20], and pRALTA from Cupriavidus taiwanensis LMG19424 codes for nitrogen fixation and legume symbiosis functions [21]. Next to these megaplasmids, other plasmids (mostly broad host range) can be present. One example is PJP4 from Cupriavidus pinatubonensis JMP134, which is a broad host range IncP-1 $\beta$ plasmid involved in the degradation of substituted aromatic pollutants [22].

The C. metallidurans mobilome is completed with a large diversity of genomic islands (GIs), integrative and conjugative elements, transposons and insertion sequence (IS) elements [7,23-25]. Many mobile genetic elements (MGEs) carry accessory genes beneficial for adaptation to particular niches (resistance, virulence, catabolic genes), but acquired genes may also impact the host by cross-talk to host global regulatory networks [26]. In addition, without accessory genes, MGEs such as IS elements can have an impact on genome plasticity and concomitant adaptability of phenotypic traits, including resistance to antibacterial agents, virulence, pathogenicity and catabolism [27]. Finally, the presence of prophages, until now not identified in C. metallidurans, may also affect many different traits and lead to phenotypic changes in the host $[28,29]$.

Recently, we showed that $C$. metallidurans strains share most metal resistance determinants irrespective of their isolation type and place [7]. In contrast, significant differences in the size and diversity of their mobilome was observed. However, our comparison was based on whole-genome hybridization to microarrays containing oligonucleotide probes present on the $\mathrm{CH} 34$ microarray. These observations triggered us to further study the diversity of the mobilome, its relation to the environment and impact on the host's global phenome. Therefore, we inventoried the mobilomes and compared the global metabolic capabilities of type strain $\mathrm{CH} 34$, strains NA1 and NA4 isolated from water sources aboard ISS [12], and H1130 isolated from an invasive human infection [15]. The global metabolic activities were assessed by employing phenotype microarrays (PMs), which highlight differences in growth requirements, nutrient utilization and sensitivity to chemicals [30].

\section{Materials and Methods}

\subsection{Strains, Media and Culture Conditions}

Bacterial strains and plasmids used in this study are summarized in Table 1. Cupriavidus metallidurans strains were routinely cultured at $30{ }^{\circ} \mathrm{C}$ in lysogeny broth (LB) or tris-buffered mineral medium (MM284) supplemented with $0.2 \%(w / v)$ gluconate [1]. Escherichia coli strains were routinely cultured at $37{ }^{\circ} \mathrm{C}$ in LB. Liquid cultures were grown in the dark on a rotary shaker at $150 \mathrm{rpm}$. For culturing on agar plates, 1.5\% agar (Thermo Scientific, Oxoid, Hampshire, UK) was added. When appropriate, the following chemicals (Sigma-Aldrich (Overijse, Belgium) 
or Fisher Scientific (Merelbeke, Belgium)) were added to the growth medium at the indicated final concentrations: kanamycin $(50 \mu \mathrm{g} / \mathrm{mL}$ for E. coli or $1500 \mu \mathrm{g} / \mathrm{mL}$ for C. metallidurans), tetracycline $(20 \mu \mathrm{g} / \mathrm{mL})$, 5-bromo-4-chloro-3-indolyl- $\beta$-D-galactopyranoside (X-Gal; $40 \mu \mathrm{g} / \mathrm{mL})$, isopropyl- $\beta$-D-thiogalactopyranoside (IPTG; $0.1 \mathrm{mM}$ ) and diaminopimelic acid (DAP; $1 \mathrm{mM}$ ).

Table 1. Strains and plasmids used in this study.

\begin{tabular}{|c|c|c|}
\hline Strain or Plasmid & Genotype/Relevant Characteristics & Reference \\
\hline \multicolumn{3}{|l|}{ STRAIN } \\
\hline \multicolumn{3}{|l|}{ Cupriavidus metallidurans } \\
\hline $\mathrm{CH} 34^{\mathrm{T}}$ & Type strain & {$[31]$} \\
\hline NA1 & Isolated from a water sample, ISS & [12] \\
\hline NA4 & Isolated from a water sample, ISS & [12] \\
\hline NA4 $\triangle$ CRISPR & $\Delta$ CRISPR::tet, $\mathrm{Tc}^{\mathrm{R}}$ & This study \\
\hline H1130 & Isolated from invasive human infection & [15] \\
\hline \multicolumn{3}{|l|}{ Escherichia coli } \\
\hline DG1 & $\begin{array}{l}\left.\text { mcrA } \Delta \text { mrr-hsdRMS-mcrBC }\left(\mathrm{r}_{\mathrm{B}}{ }^{-} \mathrm{m}_{\mathrm{B}}{ }^{-}\right) \text {}\right) \text { 80lacZ } \Delta M 15 \Delta \text { lacX74 } \\
\quad \text { recA1 araD139 } \Delta(\text { ara-leu }) 7697 \text { gall galK rpsL endA1 nupG }\end{array}$ & Eurogentec \\
\hline MFDpir & 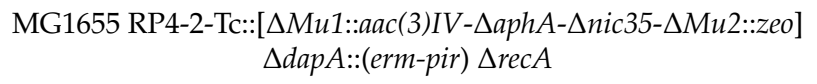 & {$[32]$} \\
\hline \multicolumn{3}{|l|}{ PLASMID } \\
\hline pK18mob & pMB1 ori, $m o b+, l a c Z, \mathrm{Km}^{\mathrm{R}}$ & [33] \\
\hline pK18mob-CRISPR & CRISPR region of NA4 in pK18mob, $\mathrm{Km}^{\mathrm{R}}$ & This study \\
\hline pK18mob-CRISPR::tet & pK18mob-CRISPR derivative, CRISPR::tet, $\mathrm{Km}^{\mathrm{R}}, \mathrm{Tc}^{\mathrm{R}}$ & This study \\
\hline pACYC184 & p15A ori, $\mathrm{Cm}^{\mathrm{R}}, \mathrm{Tc}^{\mathrm{R}}$ & [34] \\
\hline pJB3kan1 & $\mathrm{RK} 2$ minimal replicon; $\mathrm{Ap}^{\mathrm{R}}, \mathrm{Km}^{\mathrm{R}}$ & [35] \\
\hline pJB3kan1_Rmet2825 & Rmet_2825 of CH34 in pJB3kan1; $\mathrm{Km}^{\mathrm{R}}$ & This study \\
\hline
\end{tabular}

\subsection{Growth in the Presence of Metals}

Cupriavidus metallidurans $\mathrm{CH} 34, \mathrm{NA} 1, \mathrm{NA} 4$ and $\mathrm{H} 1130$ were cultivated in MM284 at $30{ }^{\circ} \mathrm{C}$ up to stationary phase $\left(10^{9} \mathrm{CFU} / \mathrm{mL}\right)$ and $10 \mu \mathrm{L}$ of a ten-fold serial dilution in $10 \mathrm{mM} \mathrm{MgSO}_{4}$ were spotted on MM284 agar plates containing various metal concentrations (Table S1). Colony forming units (CFU) were counted after $4-5$ days. Data are presented as $\log (\mathrm{N}) / \log \left(\mathrm{N}_{0}\right)$ in function of metal concentration, with $\mathrm{N}$ and $\mathrm{N}_{0}$ CFUs in the presence and absence (control) of metal, respectively.

\subsection{NA4 CRISPR Deletion Construction}

The CRISPR region of $C$. metallidurans NA4 was amplified by PCR (Phusion High-Fidelity DNA polymerase) (Fisher Scientific, Merelbeke, Belgium) with primer pairs CRSPR_Fw-Rv (Table S2), providing XbaI/HindIII restriction sites. Afterwards, this PCR product was cloned as a XbaI/HindIII fragment into the mobilizable suicide vector pK18mob. The resulting pK18mob_CRISPR plasmid from an E. coli DG1 transformant selected on LB Km50 was further confirmed by sequencing prior to amplifying of the flanking CRISPR sequences by inverse PCR (Phusion High-Fidelity DNA polymerase) with primer pair CRISPR_tet_Fw-Rv (Table S2), providing BcuI/BspTI restriction sites. At the same time, the tet gene from pACYC184 (Table 1 [34]) was amplified by PCR (Phusion High-Fidelity DNA polymerase) with primer pair Tet_Fw-Rv (Supplementary Table S1), providing BcuI/BspTI restriction sites. Afterwards, this PCR product was cloned as a BcuI/BspTI fragment into the former inverse PCR product. The resulting pK18mob-CRISPR::tet plasmid from an E. coli DG1 transformant selected on LB 
Tc20 Km50 was further confirmed by sequencing prior to conjugation (with E. coli MFDpir as donor host [32]) to C. metallidurans NA4. The resulting transformants selected on LB Tc20 were replica plated on LB Tc20 and LB Km1500. NA4 $\triangle$ CRISPR::tet cells resistant to Tc20 but sensitive to Km1500 were further confirmed by sequencing.

\subsection{Construction of Plasmids}

PCR amplification of $C$. metallidurans $\mathrm{CH} 34$ Rmet_2825 was performed on genomic DNA from C. metallidurans $\mathrm{CH} 34$ with primer pair Rmet2825_Fw-Rv (Table S2). This amplicon was subsequently cloned into pJB3kan1, which was linearized by PCR amplification with the primers pJB3kan1_Fw-Rv (Table S2), using the GeneArt ${ }^{\mathrm{TM}}$ Seamless Cloning and Assembly Enzyme Mix (Fisher Scientific, Merelbeke, Belgium). The resulting pJB3kan1-Rmet2825 plasmid from E. coli DG1 transformants selected on LB Km50 was further confirmed by sequencing prior to transformation to E. coli MFDpir.

\subsection{Conjugation Assay for Testing CRISPR-Cas}

Donor (E. coli MFDpir pJB3kan1-Rmet2825) and recipient (C. metallidurans NA4 or NA4 $\triangle$ CRISPR::tet) were grown overnight at $37^{\circ}$ in LB Km50 DAP, and at $30^{\circ}$ in $\mathrm{LB}$, respectively. Fifty $\mu \mathrm{L}$ of donor and recipient were spotted on a $0.45 \mu \mathrm{m}$ Supor ${ }^{\circledR}$ membrane disc filter (Pall Life Sciences, Hoegaarden, Belgium) that was put on a LB DAP plate. After overnight incubation at $30^{\circ} \mathrm{C}$, cells were resuspended in $1 \mathrm{~mL}$ of $10 \mathrm{mM} \mathrm{MgSO}_{4}$ and 10 -fold serial diluted on $\mathrm{LB} \mathrm{Km} 50 \mathrm{DAP}\left(37^{\circ} \mathrm{C}\right), \mathrm{LB}\left(30^{\circ} \mathrm{C}\right)$ and LB Km1500 plates $\left(30^{\circ} \mathrm{C}\right)$ to count CFU of donors, recipients and transconjugants, respectively. Conjugation frequency was measured as the number of transconjugants per donor cell (T/D) and per recipient cell $(\mathrm{T} / \mathrm{R})$.

\subsection{Plasmid Profiling}

The extraction of megaplasmids was based on the method proposed by Andrup et al. [36]. Extracted plasmid DNA was separated by horizontal gel electrophoresis (0.5\% Certified Megabase agarose gel (Bio-Rad, Temse, Belgium) in $1 \mathrm{X}$ TBE buffer, $100 \mathrm{~V}, 20 \mathrm{~h}$ ) in a precooled $\left(4^{\circ} \mathrm{C}\right)$ electrophoresis chamber. After GelRed staining ( $30 \mathrm{~min}+$ overnight destaining at $4{ }^{\circ} \mathrm{C}$ in ultrapure water), DNA was visualized and images captured under UV light transillumination (Fusion Fx, Vilber Lourmat, Collégien, France).

\subsection{Phenotype Microarray Analysis}

Phenotype microarray (PM) analysis was performed using the OmniLog ${ }^{\circledR}$ automated incubator/reader (Biolog Inc., Hayward, CA, USA) following manufacturer's instruction (PM procedures for E. coli and other GN Bacteria version 16-Jan-06 with slight modifications). Briefly, cells were suspended in Biolog's inoculation fluid IF-0a (1x) until an optical density (600 nm) of 0.2 was reached. Subsequently, a 1:50 dilution was made in IF-0a (1x) containing dye mix A. Furthermore, $2 \mathrm{mM}$ sodium succinate and $2 \mu \mathrm{M}$ ferric citrate (Sigma-Aldrich, Overijse, Belgium) were used as carbon sources in PM 3 till 8. All 20 plates (PM-1 through PM-20) inoculated with bacterial cell suspensions, were incubated at $30{ }^{\circ} \mathrm{C}$ and cell respiration was measured every $30 \mathrm{~min}$ for $144 \mathrm{~h}$. Raw kinetic data were retrieved using the OmniLog_OL_PM_FM/Kin 1.30-: File Management/Kinetic Plot Version software of Biolog. Analysis was carried out with the R-library OPM (version 1.3.64) [37,38]. The area under the curve (AUC) threshold to decide whether a strain is or is not growing in a specific well of the PM, was derived by plotting the AUC values of all PM reactions for each strain, showing in all conditions an almost bimodal distribution. The AUC threshold (one value for all four strains) was determined as the value separating both major peaks (threshold value of 8000) (Figure S1). Negative control wells that contained the inoculated Omnilog ${ }^{\mathrm{TM}}$ growth medium without any substrate were measured to normalize differences in inocula and redox dye oxidation between samples. 


\subsection{Computational Methods}

The pan-genome analysis was performed via the MaGe platform [39], which uses MicroScope gene families (MICFAM) that are computed with an algorithm implemented in the SiLiX software [40]. The alignment constraints to compute the MICFAM families were $80 \%$ amino-acid identity and $80 \%$ amino-acid alignment coverage. The MICFAM is part of the core-genome if associated with at least one gene from every compared genome (see Table S3 for complete data set).

A phylogenetic tree of the genomes was constructed via the MaGe platform from the pairwise genome distances using a neighbor-joining algorithm. The pairwise genome distance was calculated with Mash [41].

The CARD (comprehensive antibiotic resistance database) [42] implementation within the MaGe platform [39] was used to identify known resistance determinants and associated antibiotics. All predictions were strict as defined by CARD, meaning a match above the CARD curated bitscore cut-offs [42-44].

A BLAST search against BacMet (antibacterial biocide and metal resistance genes database) was used to inventory genes predicted to confer resistance to metals and/or antibacterial biocides [45]. The alignment constraints were $35 \%$ amino-acid identity and $80 \%$ amino-acid alignment coverage.

The different constraints used to compute the MICFAM families and CARD/BacMet BLAST hits can result in minor differences in the number of core genome genes from a particular strain that results in a positive CARD/BacMet hit.

\section{Results and Discussion}

Four C. metallidurans strains were selected: type strain CH34 [3], strain NA1 and NA4 isolated from the drinking water systems onboard the International Space Station that were analyzed previously and had mobilomes divergent from that of $\mathrm{CH} 34$ [7], and strain H1130, recently isolated from an invasive human infection [15]. This selection allows comparing the type strain with two strains isolated from a similar environment but with different mobilomes (at least based on elements known in $\mathrm{CH} 34$ [7]) and an isolate from a human infection.

\subsection{Comparison of General Genome Features}

The genome of $C$. metallidurans NA1, NA4 and H1130 was previously sequenced $[46,47]$ and estimated to be 6,833,318 bp, 7,370,364 bp and 7,225,099 bp, respectively (with type strain CH34 being $6,913,352 \mathrm{bp}[3])$. The $\mathrm{G}+\mathrm{C}$ content of the genomes are very similar to each other, with $63.76 \%$, $63.27 \%, 63.50 \%$ and $63.82 \%$ for NA1, NA4, H1130 and CH34, respectively. NA4 contained the most coding sequences (CDSs) (7467), followed by H1130 (7032), NA1 (6815) and CH34 (6757). All strains contained multiple replicons, namely, one chromosome, one chromid and megaplasmids (>100 kb [19]). Strain NA1 carries two megaplasmids. Strain NA4 carries three megaplasmids and one plasmid. Strain H1130 carries only one megaplasmid (Figure 1).

The core genome contains 4697 MICFAM gene families shared by all four strains, which relates to $70.9 \%, 70.2 \%, 65.4 \%$ and $69.9 \%$ of the total CDSs of CH34, NA1, NA4 and H1130, respectively. This means that roughly $30 \%$ to $35 \%$ of the CDSs belong to the variable (shared by two or three strains) or strain-specific genome (Figure 2). Strains CH34 and NA4 shared the most gene families (Figure 3). Furthermore, the Mash-distance-based phylogeny (Figure 4) indicated that NA4 and CH34 were the most closely related. In addition, NA4 shared more gene families with H1130 and CH34 than with NA1, which corresponded with the phylogenetic distance. These data indicated that NA1 and NA4 were not the two most similar strains, despite their isolation from the same environment. 


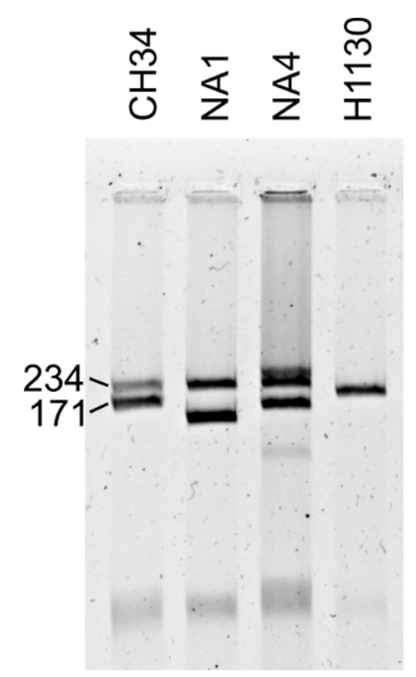

Figure 1. Agarose gel electrophoresis of Cupriavidus metallidurans CH34, NA1, NA4 and H1130 (mega)plasmid DNA. The characterized CH34 megaplasmids pMOL30 (234 kb) and pMOL28 (171 kb) serve as reference.

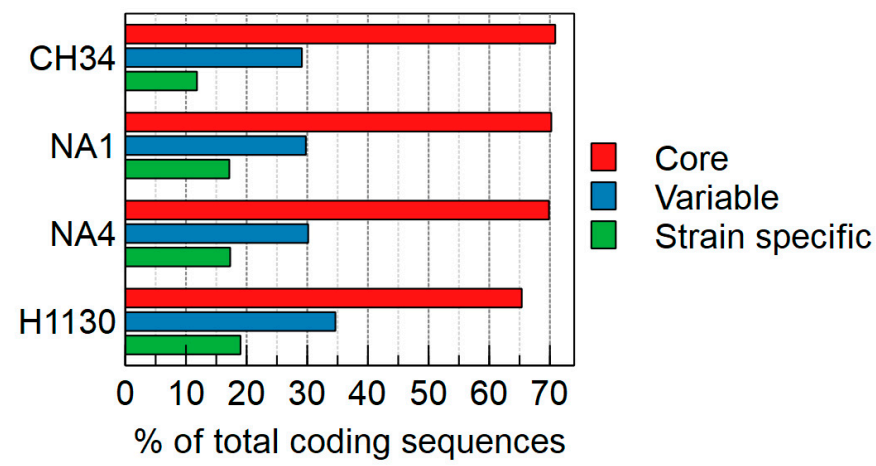

Figure 2. Percentage of coding sequences (CDSs) belonging to the core, variable (shared by two or three strains) and strain-specific genome of Cupriavidus metallidurans CH34, NA1, NA4 and H1130.

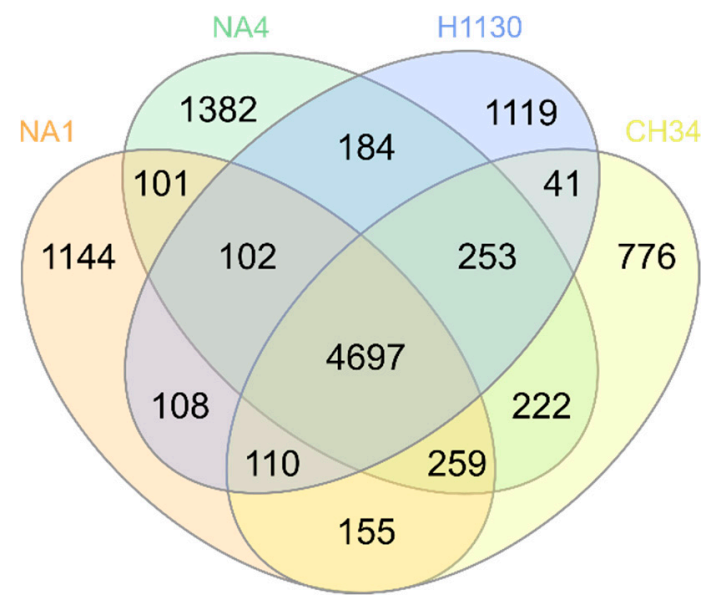

Figure 3. Venn diagram displaying the distribution of shared MicroScope gene families (MICFAM) among C. metallidurans CH34, NA1, NA4 and H1130. 


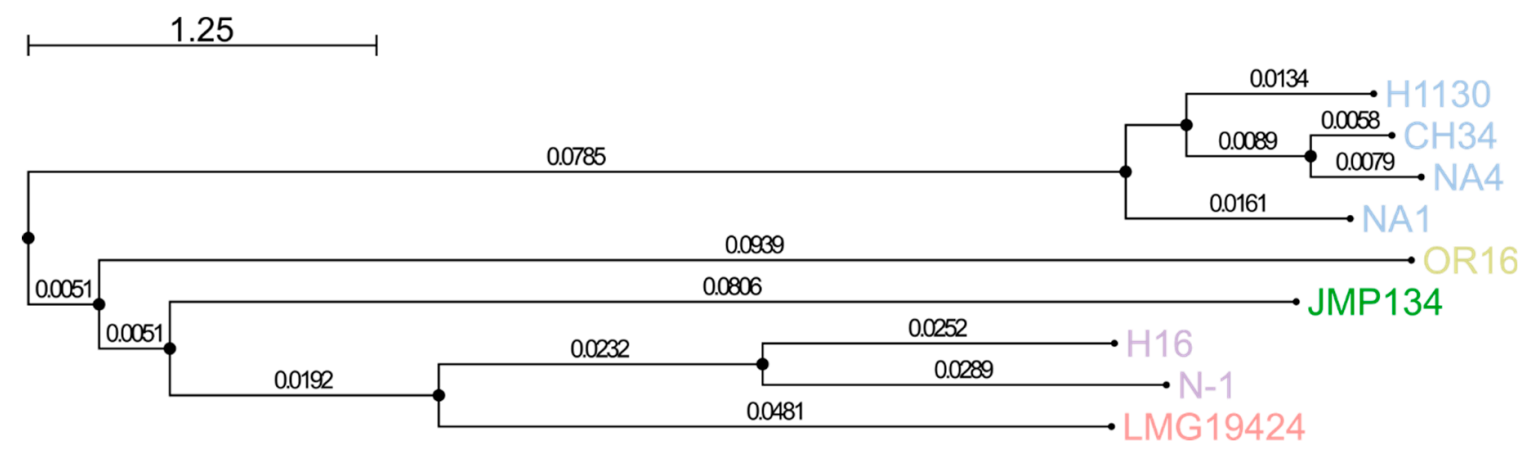

Figure 4. Neighbor-joining phylogenetic tree of C. metallidurans CH34, NA1, NA4 and H1130, based on the genome pairwise distance matrix calculated with Mash. Cupriavidus basilensis: OR16, Cupriavidus pinatubonensis: JMP134, Cupriavidus necator: H16 and N-1, and Cupriavidus taiwanensis: LMG19424 were included for comparison.

Evidently, with 1827 Microscope gene families shared with Cupriavidus taiwanensis LMG19424, Cupriavidus necator H16, Cupriavidus pinatubonensis JMP134, Cupriavidus basilensis OR16 and Cupriavidus necator $\mathrm{N}-1$, the $C$. metallidurans strains share more gene families among each other than with strains of different Cupriavidus species. Strains CH34, NA1, NA4 and H1130 shared 1977 gene families unique to the $C$. metallidurans species.

The COGnitor module [48] implemented in the MaGe platform was used to compare the CDSs of the core, variable and specific genome assigned to a COG (clusters of orthologous groups) functional category (Figure 5). The latter indicated that for all four strains, COG L (replication, recombination and repair) and $U$ (intracellular trafficking and secretion) are overrepresented on the variable plus specific genome. Other COGs were also significantly overrepresented on the variable plus specific genome for particular strains. For instance, COG D (cell cycle control, division and partitioning) for CH34, NA4 and H1130, and COG V (defense mechanisms) for NA1 and NA4 (see Figure 5 for all significant overrepresentations).

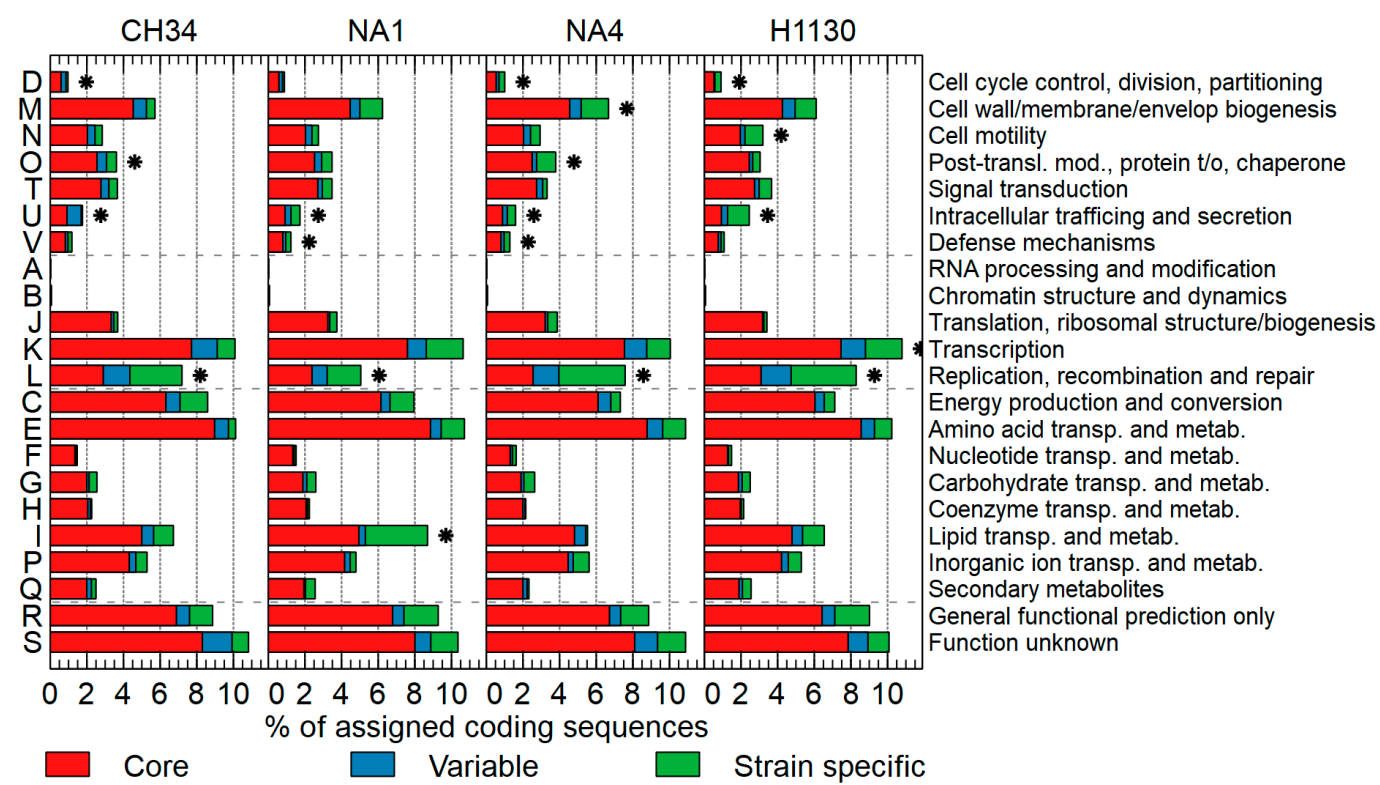

Figure 5. Percentage of CDSs assigned to a COG (clusters of orthologous groups) functional class (general categories: cellular processes and signaling: $\mathrm{D}, \mathrm{M}, \mathrm{N}, \mathrm{O}, \mathrm{T}, \mathrm{U}, \mathrm{V}$; information storage and processing: A, B, J, K, L; metabolism; C, E, F, G, H, I, P, Q; poorly characterized: R, S) belonging to the core, variable of strain-specific genome of $C$. metallidurans $\mathrm{CH} 34, \mathrm{NA1}$, NA4 and H1130. * Significant ( $p<0.05$; based on hypergeometric distribution) overrepresentation of COG on variable + specific compared to the core genome. 


\subsection{The Mobilome}

Recently, we showed that $C$. metallidurans strains have substantial differences in the diversity and size of their mobile gene pool [7]. However, since this comparison was based on whole-genome hybridization to microarrays containing type strain $\mathrm{CH} 34$ oligonucleotide probes, the presence of MGEs other than those in CH34 could not be assessed. Here, the mobilomes of NA1, NA4 and H1130 (including IS elements, transposons, genomic islands and prophages) as well as the presence of CRISPR-Cas systems were scrutinized.

\subsubsection{Insertion Sequence Elements and Transposons}

ISFinder [49] and ISSaga [50] (+ manual curation) were used to create an inventory of the IS elements, which identified 57, 25, 33 and 91 putative IS elements in CH34 [24], NA1, NA4 and H1130, respectively. It must be noted that this list is based on a draft genome assembly for NA1, NA4 and H1130, which could have an impact on the actual number. Possible identical IS elements present in multiple copies will only be represented as one contig in the genome assembly, as such leading to an underestimation of the number of IS elements in the respective genome [51]. Active IS transposition in CH34 was already observed for ISRme1, ISRme3, ISRme5, ISRme15, IS1086, IS1087B, IS1088 and IS1090 [24,52-58]. Transposition activity of ISRme5 > IS1088 > ISRme3 > IS1087B > IS1090 > IS1086 > ISRme15, at least into the $c n r$ target after exposure of AE126, a derivative of $\mathrm{CH} 34$ cured from plasmid pMOL30 carrying the main zinc resistance determinant, to $0.8 \mathrm{mM} \mathrm{Zn}^{2+}$ [58]. Some of these active IS elements are also carried by NA1 (2 ISRme3 copies), NA4 (1 ISRme1, 4 ISRme4 and 1 ISRme5 copy) and H1130 (16 ISRme3 copies) (based on 98\% DNA sequence identity cut-off). Next to transposition, IS elements can also cause more extensive/general loss of genetic information by recombination events between identical individual IS copies, e.g., loss of the $\mathrm{CH} 34$ genes involved in autotrophy by IS1071-mediated excision [24]. Similar observations of IS1071-mediated rearrangements affecting the metabolic potential of the host have been described for Comamonas sp. strain JS46 [59] and Cupriavidus pinatubonensis JMP134 [60]. Thus, these IS elements in CH34, NA1, NA4 and H1130 can play a multifaceted, pivotal role in the adaptation to stress conditions (as shown for CH34) $[27,58]$.

The $\mathrm{CH} 34$ genome harbors five distinct transposon families totaling 19 intact transposons. The transposition modules of four transposons are related to those of mercury transposons with Tn4378, Tn4380 and Tn6050 belonging to the Tn21/Tn501 family, and Tn6048 to the Tn5053 family [61]. The transposition module of Tn6049 could not be categorized. Tn6048, Tn6049 and mercury transposons are also conserved in NA1 (one Tn6048 copy, one Tn6049 copy), NA4 (3 mercury transposons, 3 Tn6049 copies) and H1130 (4 mercury transposons). Tn6050 appeared to be only present in $\mathrm{CH} 34$. No other transposons were identified.

\subsubsection{Genomic Islands}

The MaGe platform was used to scrutinize the presence of genomic islands (GIs), including those previously identified in $\mathrm{CH} 34$. The largest island $(109 \mathrm{~kb})$ on the chromosome of $\mathrm{CH} 34$ belongs to the large pKLC102/PAGI-2 family of elements that share a core gene set and are integrated downstream of tRNA genes [62,63]. A similar element is present in NA1 (2 copies), NA4 and H1130 as shown by progressive Mauve alignment [64] (Figure S2). The Tn4371-family of integrative and conjugative elements CMGI-2, CMGI-3 and CMGI-4 of CH34 were previously designated $\mathrm{ICE}_{\mathrm{Tn} 4371} 6054, \mathrm{ICE}_{\mathrm{Tn} 4371} 6055$ and $\triangle \mathrm{ICE}_{\mathrm{Tn} 4371} 6056$, respectively [65]. CMGI-2 (ICE $\mathrm{Tn}_{\mathrm{Tn} 371} 6054$ ) and CMGI-3 (ICE $\mathrm{Tn4371}_{\text {6055) }}$ are responsible for $\mathrm{CH} 34$ 's ability to grow on aromatic compounds and to fix carbon dioxide, respectively [7,24]. No Tn4371-family genomic island was identified in NA4. One Tn4731-family element was identified in NA1, which is highly similar to previously identified

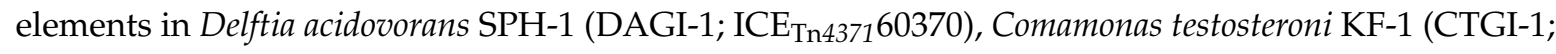
$\left.\mathrm{ICE}_{\mathrm{Tn} 4371} 6038\right)$ and the partial CMGI-4 $\left(\mathrm{ICE}_{\mathrm{Tn} 43716056)}\right.$ of $\mathrm{CH} 34[25,65]$. The island carries an RND-driven efflux system. In H1130, two Tn4371-family genomic islands were identified, one carrying 
12 genes (putatively involved in ion transport), while the second could not be correctly defined as the integration/excision and stabilization/maintenance module up to $r l x S$ (encoding a relaxase protein) are not located on the same contig as the transfer module (starting from traR coding for a transcriptional regulator). Therefore, the accessory genes that are typically located between $r l x S$ and traR in Tn4371-family members could not be properly assessed [65]. All other GIs on CH34's chromosome were not found in the other strains, except CMGI-5 in NA1. CMGI-C and CMGI-E, previously identified on CH34's chromid, are absent in all strains. CMGI-A, -B and -D are conserved in NA4 and H1130, but show limited synteny with NA1. No other genomic islands could be clearly identified in NA1 or NA4. One other genomic island was clearly noticeable in H1130. This 87 $\mathrm{kb}$ region, which is absent in CH34, NA1 and NA4, is syntenic with an 80-kb cluster located on the 1.47-Mbp megaplasmid of Burkholderia xenovorans LB400. In B. xenovorans LB400, this Dit island encodes proteins of abietane diterpenoids metabolism and mediates growth on abietic acid, dehydroabietic acid, palustric acid and 7-oxo-dehydroabietic acid [66] (not included in the phenotypic microarray). Abietane diterpenoids are tricyclic, C-20, carboxylic acid-containing compounds produced by plants and are a key component of the defense systems of coniferous trees [66,67]. This observation also adds evidence to the mobility of this cluster and its distribution among proteobacterial genomes [66]. In addition, two smaller regions ( 13.6 and $10.3 \mathrm{~kb}$ ) carrying genes coding for unknown functions and a tyrosine-based site-specific recombinase were identified.

\subsubsection{Prophages}

The presence of prophages was scrutinized via PHASTER [68] and showed no prophages in type strain $\mathrm{CH} 34$ (which was already known) and the presence of intact prophages in NA4 and H1130 as well as incomplete/remnants in H1130, NA1 and NA4 (Table 2). Although mitomycin C exposure did not result in prophage induction (data not shown), a derivative of NA4 exposed to uranium lost the $43.6 \mathrm{~kb}$ region predicted as an intact prophage (unpublished data).

Table 2. Prophage detected in C. metallidurans NA1, NA4 and H1130.

\begin{tabular}{|c|c|c|c|c|c|c|c|}
\hline Strain & Size $^{a}$ & Completeness $^{b}$ & Score ${ }^{c}$ & $\#^{d}$ & Position & Most Common Phage ${ }^{e}$ & GC $\%$ \\
\hline \multirow[t]{2}{*}{ NA1 } & 27.9 & questionable & 90 & 32 & $528,474-556,451$ & Ralsto_RS138 (NC_029107; 7) & 65.35 \\
\hline & 17.7 & incomplete & 20 & 21 & $554,542-572,263$ & Pseudo_NP1 (NC_031058; 3) & 64.23 \\
\hline \multirow[t]{6}{*}{ NA4 } & 43.6 & intact & 100 & 50 & $1,706,628-1,750,233$ & Bordet_BPP_1 (NC_005357; 18) & 64.94 \\
\hline & 6.1 & intact & 100 & 10 & $1,941,664-1,947,835$ & Ralsto_PE226 (NC_015297; 6) & 60.08 \\
\hline & 45.2 & intact & 150 & 41 & $2,145,854-2,191,126$ & Burkho_Bcep176 (NC_007497; 11) & 61.83 \\
\hline & 8 & incomplete & 30 & 10 & $2,181,367-2,189,450$ & Gordon_Nymphadora (NC_031061; 2) & 62.44 \\
\hline & 120.5 & intact & 130 & 125 & $2,248,504-2,369,042$ & Salmon_118970_sal3 (NC_031940; 14) & 61.84 \\
\hline & 44.5 & incomplete & 30 & 39 & $2,545,435-2,589,959$ & Pseudo_JBD44 (NC_030929; 5) & 63.89 \\
\hline \multirow[t]{5}{*}{ H1130 } & 19.3 & incomplete & 30 & 21 & $1,470,543-1,489,908$ & Burkho_phiE125 (NC_003309; 3) & 61.27 \\
\hline & 12.7 & incomplete & 40 & 19 & $1,505,965-1,518,710$ & Bacill_SP_15 (NC_031245; 5) & 63.39 \\
\hline & 7.9 & incomplete & 30 & 9 & $2,763,200-2,771,108$ & Entero_phi92 (NC_023693; 4) & 58.60 \\
\hline & 48.4 & intact & 110 & 73 & $6,748,679-6,797,173$ & Salmon_SEN34 (NC_028699; 22) & 62.09 \\
\hline & 16 & incomplete & 50 & 29 & $7,110,429-7,126,525$ & Clostr_phiCT453B (NC_029004; 4) & 61.04 \\
\hline
\end{tabular}

${ }^{\mathrm{a}}$ Size in $\mathrm{kb} ;{ }^{\mathrm{b}}$ Prediction of whether the region contains an intact or incomplete prophage and ${ }^{\mathrm{c}}$ score based on PHASTER criteria [68]; ${ }^{\mathrm{d}}$ number of proteins; ${ }^{\mathrm{e}}$ the phage with the highest number of proteins most similar to those in the region (between parentheses: accession number; number of proteins).

\subsubsection{CRISPR-Cas}

The CRISPR-Cas system is an adaptive immunity system that stores memory of past encounters with foreign DNA in spacers that are inserted between direct repeats in CRISPR arrays [69]. CRISPR-Cas systems were detected with CRISPRfinder [70] and CRISPRDetect [71] (default settings). Only positive hits with both were further examined, resulting in the identification of 1 CRISPR-Cas system in NA4. CRISPRTarget [72] identified 5 spacer sequences related to genomic island CMGI-5 of CH34 (which is also present in NA1). CMGI-5 is probably a plasmid remnant and contains besides hypothetical genes, some typical plasmid-related genes such as rep $A, \operatorname{tra} Y$, mobA and mobB. To assess if the identified system is active, the conjugation frequency of plasmid pJB3kan1 carrying 
the CMGI-5 repA gene (pJB3kan1_Rmet2825; containing one spacer) was determined for the parental and CRISPR-deleted NA4 strain. CRISPR deletion in NA4 increased the conjugation efficiency 33-fold, indicating an active CRISPR-Cas system in NA4 (Figure 6).

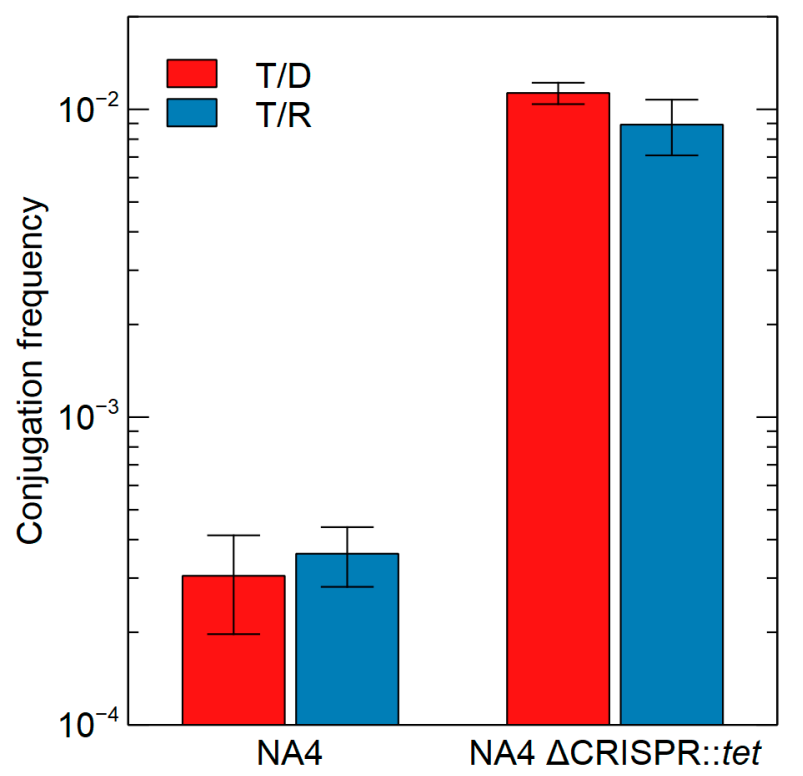

Figure 6. Conjugation frequency of pJB3kan1_Rmet2825 (containing one spacer identified in the NA4 CRISP-Cas system) from donor E. coli MFDpir to recipient C. metallidurans NA4 and NA4 $\triangle$ CRISPR::tet, respectively. Median values plus corresponding calculated standard deviations across biological triplicates are shown $(\mathrm{T} / \mathrm{D}=$ conjugation frequency per donor; $\mathrm{T} / \mathrm{R}=$ conjugation frequency per recipient).

\subsection{The Resistome}

\subsubsection{Antibiotic Resistance}

The CARD [42] implementation within the MaGe platform [39] was used to identify known resistance determinants and associated antibiotics. The latter predicted 33, 36, 33 and 39 proteins involved in antibiotic resistance in CH34, NA1, NA4 and H1130, of which 31, 31, 30 and 39 belonged to the core genome, respectively. No marked difference in tolerance to antibiotics was observed.

\subsubsection{Metal Resistance}

The antibacterial biocide and metal resistance genes database (BacMet) was used to create an inventory of genes predicted to confer resistance to metals and/or antibacterial biocides [45]. This showed 302, 282, 337 and 302 proteins involved in biocide and metal resistance in CH34, NA1, NA4 and H1130, respectively. Most genes belonged to the core genome (221, 246, 276 and 251 for CH34, NA1, NA4 and H1130, respectively). The compounds (metal and chemical class) to which these genes confer resistance are very similar for all four strains (Figure 7). Genes conferring resistance to nickel, copper, cobalt and the chemical classes acridine and phenanthridine were the most abundant.

For $\mathrm{CH} 34$, the predicted genes contained 68 out of the 174 genes that were previously identified to be related to metal resistance (for an overview see [2,3]). Specific analysis of these 174 proteins showed that almost all are conserved in NA1, NA4 and H1130. Exceptions are (i) the accessory cluster related to chromate resistance in H1130, (ii) the hmz cluster in NA4 and H1130, (iii) cdfX in NA1, NA4 and H1130, and (iv) the dax/gig cluster in NA1. The latter three are all located on a genomic island. The gene cluster related to chromate resistance on pMOL28 from CH34 contains five additional genes that are strongly induced by chromate in CH34 [73] as well as for the homologous system in Arthrobacter sp. FB24 (both at the gene and protein level) [74,75]. The hmz cluster is a HME-RND-driven 
system, belonging to the HME3b (Heavy Metal Efflux) subfamily of the RND superfamily, with no known substrate and transcriptionally silent in C. metallidurans $\mathrm{CH} 34[5,73,76]$. The cdfX gene of $\mathrm{CH} 34$ encodes a putative permease (211 amino acid residues and six predicted transmembrane $\alpha$-helices) that shares 87\% amino-acid identity with PbtF from Achromobacter xylosoxidans A8 [5]. Expression of pbtF in A. xylosoxidans A8 was induced by $\mathrm{Pb}^{2+}, \mathrm{Cd}^{2+}$ and $\mathrm{Zn}^{2+}$, and although $\mathrm{PbtF}$ showed measurable $\mathrm{Pb}^{2+}$-efflux activity, it did not confer increased metal tolerance in E. coli GG48 [77]. The dax cluster [73], which was renamed gig for "gold-induced genes" in Wiesemann et al. [78], is induced by $\mathrm{Ag}^{+}$and $\mathrm{Au}^{3+}[73,79]$ but not essential for gold resistance [78].

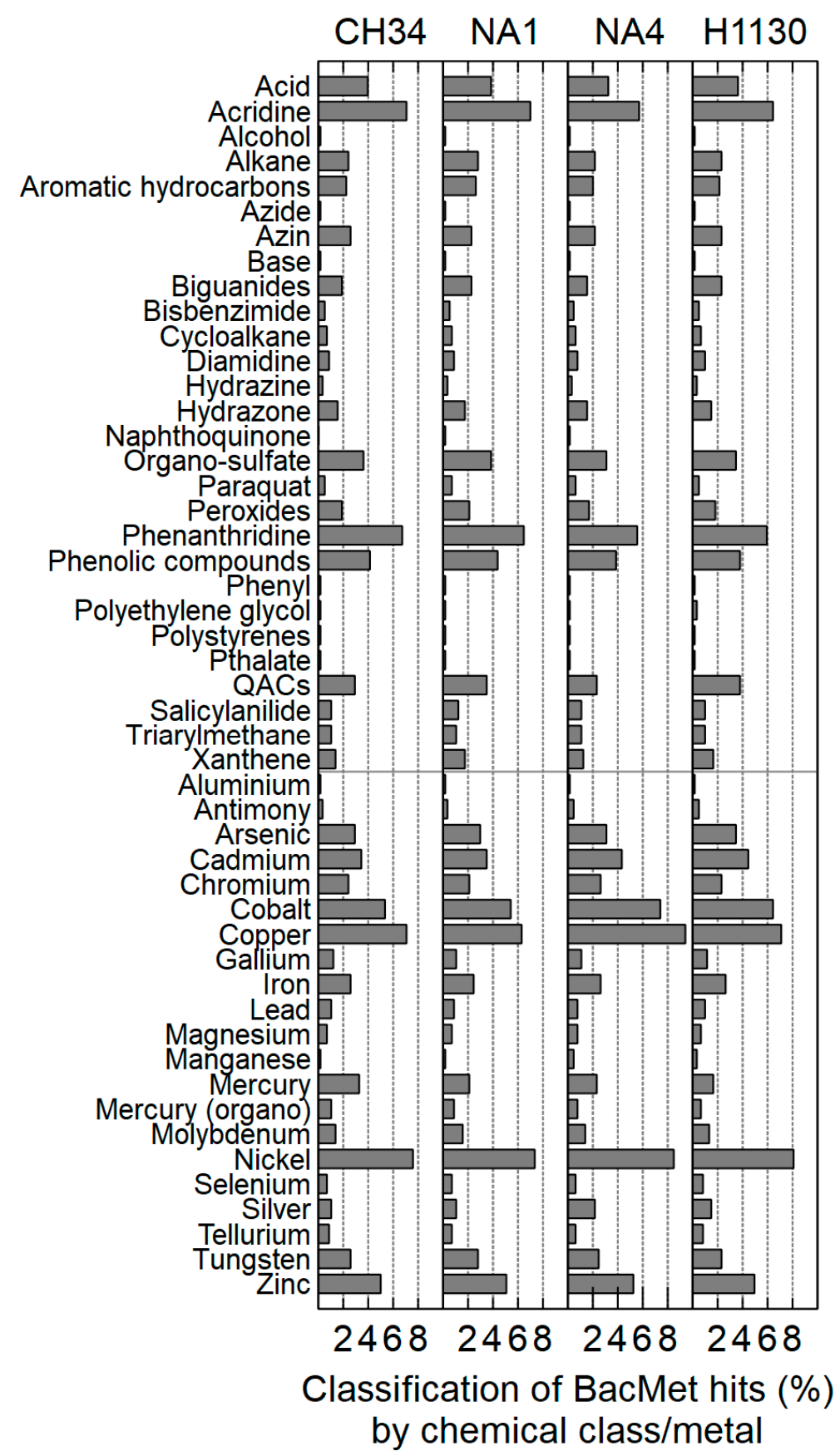

Figure 7. Inventory of $\mathrm{C}$. metallidurans $\mathrm{CH} 34, \mathrm{NA} 1, \mathrm{NA} 4$ and $\mathrm{H} 1130$ genes conferring resistance to metals/chemical classes based on the BacMet database (antibacterial biocide and metal resistance genes database). 
In agreement with the conservation of these metal resistance determinants, growth in the presence of increasing metal concentrations showed only minor differences between CH34, NA1, NA4 and H1130 (Figure 8). Moreover, the minor strain-dependent differences (see above) did not mediate differences in metal resistance (Figure 8). Essentially, the most noticeable difference in growth was observed in the presence of $\mathrm{Ni}^{2+}$, with higher concentrations tolerated by NA4 and H1130. Initially, the $n c c C B A$ locus, which is inactivated in $\mathrm{CH} 34$ because of a frame shift mutation, was put forward as a possible explanation [12]. However, the frame shift mutation in $n c c B$ is present in all four strains. However, NA4 and H1130 carry a second nccYXHCBAN locus coding for an RND-driven efflux system involved in $\mathrm{Ni}^{2+}$ and $\mathrm{Co}^{2+}$ resistance. This locus is homologous to that of C. metallidurans 31A and KT02, which has been shown to be responsible for resistance to $40 \mathrm{mM} \mathrm{Ni}^{2+}$ [80], and is likely responsible for the observed differences. In addition, although the nimBAC locus, coding for an RND-driven efflux system putatively involved in $\mathrm{Ni}^{2+}$ and $\mathrm{Co}^{2+}$ resistance [5], is only inactivated in $\mathrm{CH} 34$ (via ISRme3 insertion) and not in NA1, NA4 and H1130, growth in the presence of $\mathrm{Ni}^{2+}$ is similar for NA1 and $\mathrm{CH} 34$. Other observations are the lower resistance of NA1 to $\mathrm{Cd}^{2+}$ and to lesser extent $\mathrm{Co}^{2+}$ and $\mathrm{Ag}^{+}$. However, based on the current data, no hypotheses can be put forward to explain these observations.
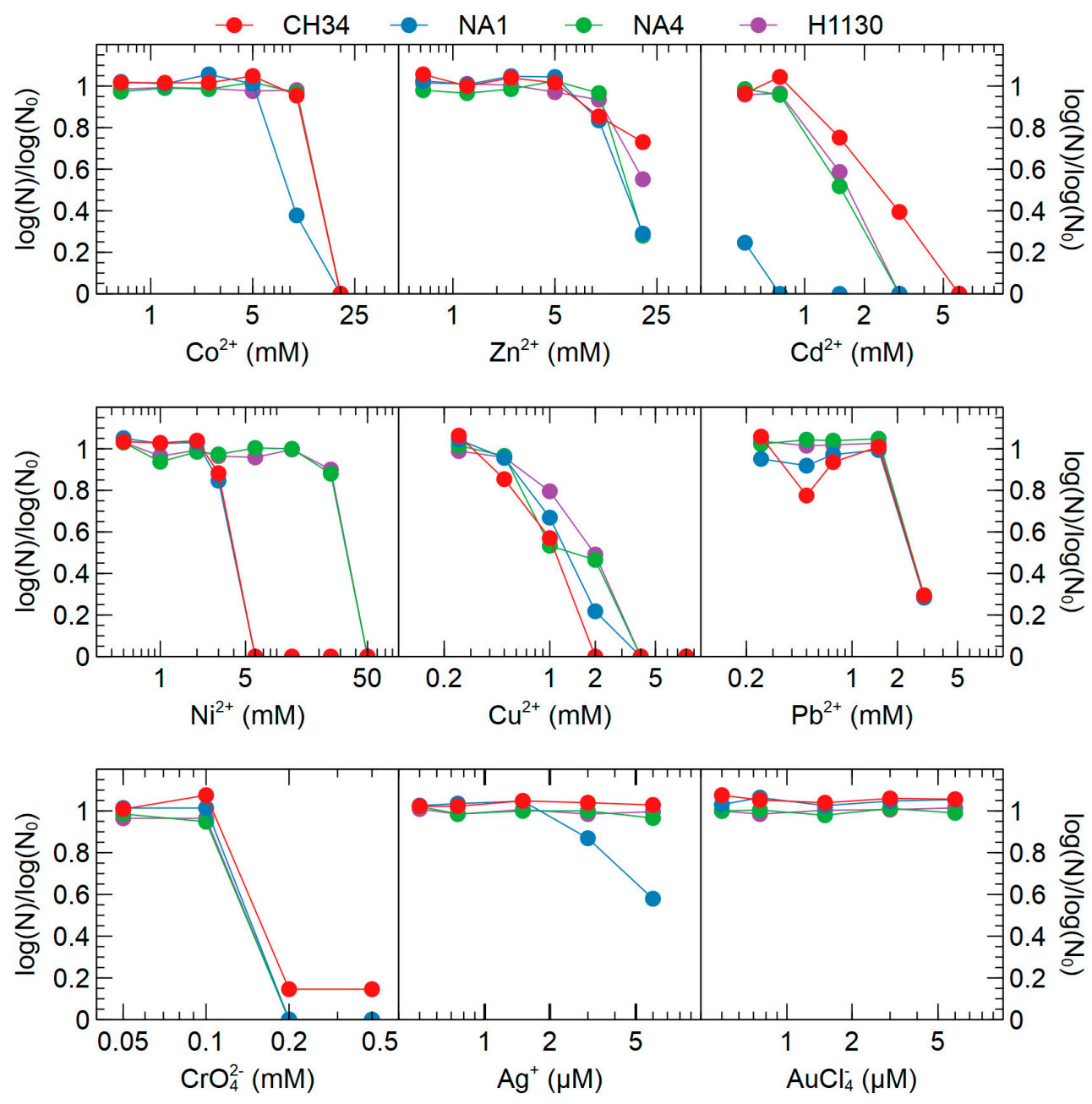

Figure 8. Viable count of $C$. metallidurans $\mathrm{CH} 34$, NA1, NA4 and H1130 grown in the presence of various metal concentrations (Table S2). Data are presented as $\log (\mathrm{N}) / \log \left(\mathrm{N}_{0}\right)$ in function of metal concentration, with $\mathrm{N}$ and $\mathrm{N}_{0}$ the colony forming units (CFUs) in the presence and absence (control) of metal, respectively. 


\subsection{Phenotypic Microarrays}

In order to scrutinize functional differences between the four C. metallidurans strains, phenotypic characterization with OmniLog Phenotypic Microarrays (PMs) was conducted. Area under the curve (AUC) values were calculated and a threshold cut-off (8000) was applied to discriminate a positive (growth) from a negative (no-growth) reaction. This revealed an overall phenotypic similarity among the four strains, with 1744 out of the 1920 assays shared (Figures 9-11).

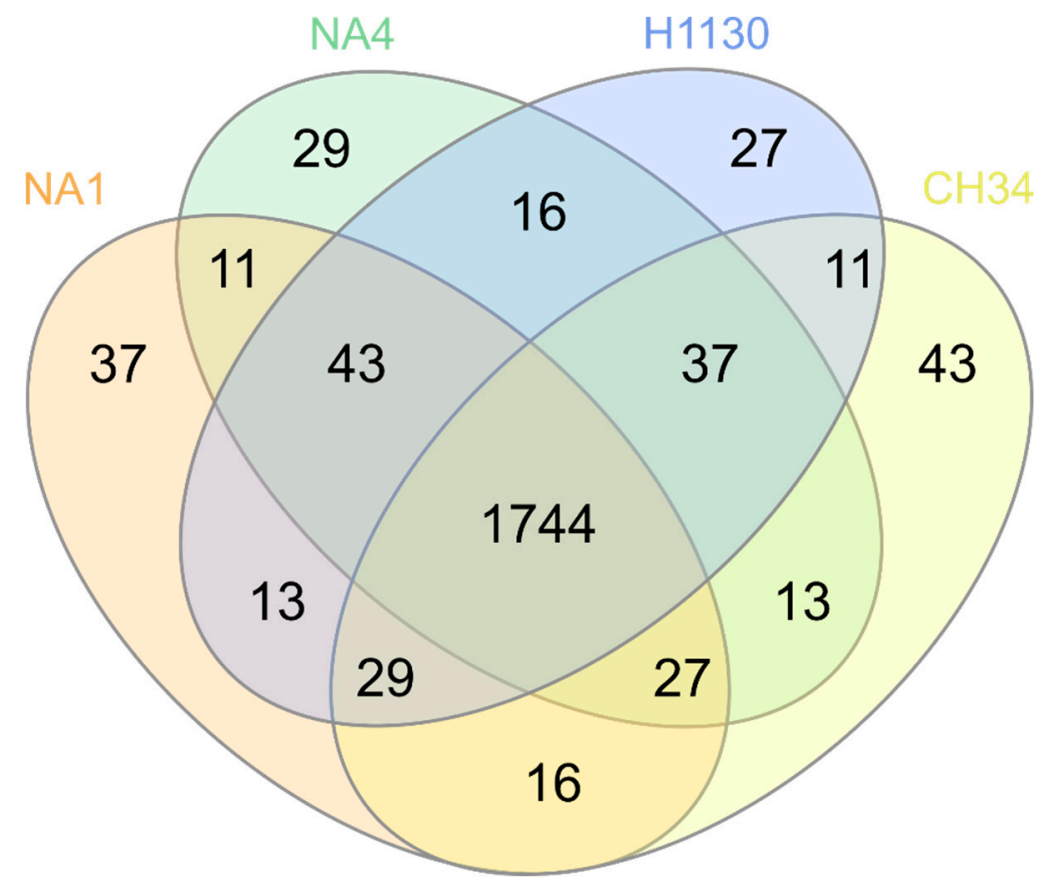

Figure 9. Venn diagram displaying the distribution of OmniLog phenotypic assays shared among C. metallidurans CH34, NA1, NA4 and H1130. 


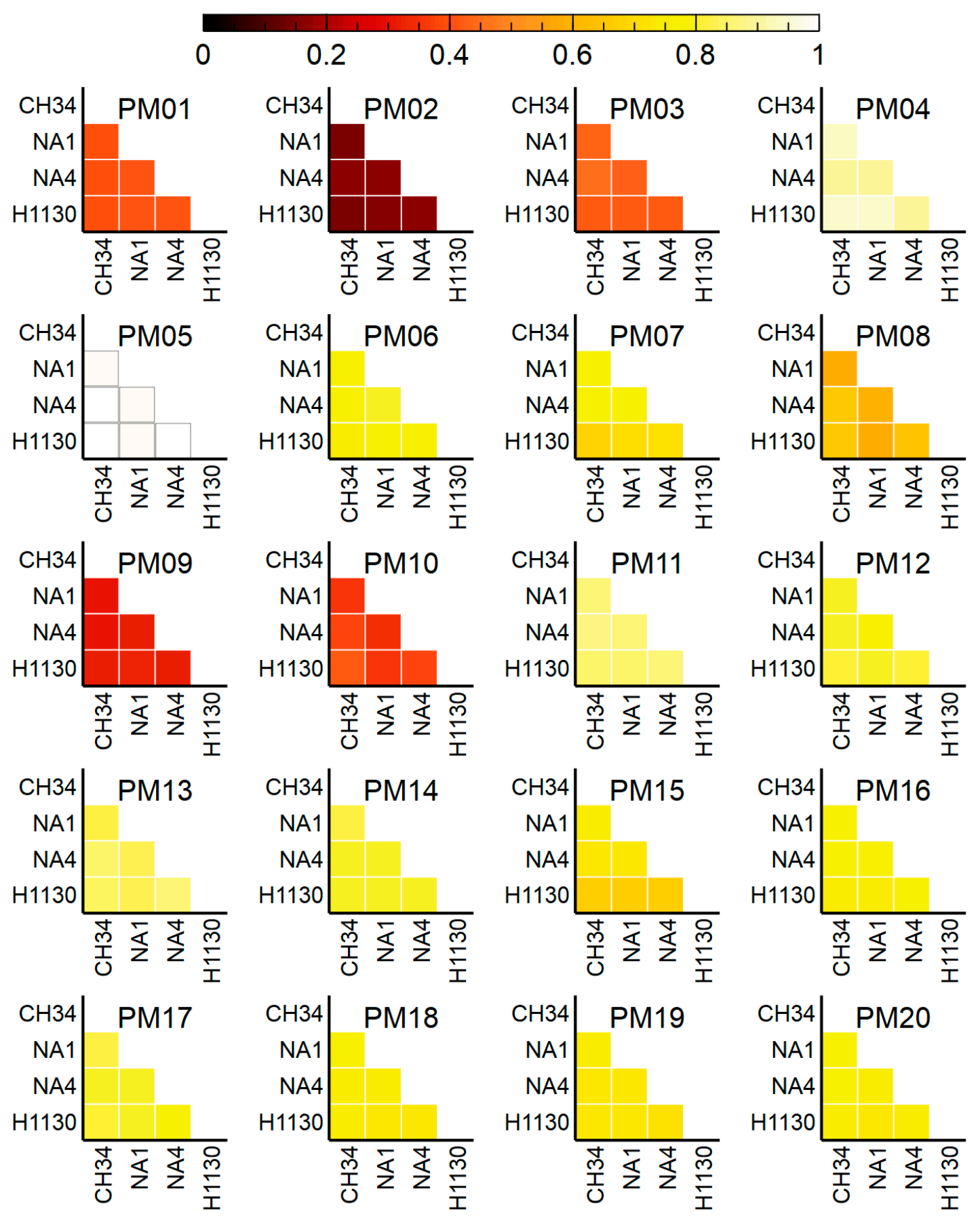

Figure 10. Overview of positive (growth) OmniLog phenotypic assays shared by C. metallidurans CH34, NA1, NA4 and H1130 for each PM plate (with 1 being all 96 assays). The assays on each PM plate are detailed in Table S4. 


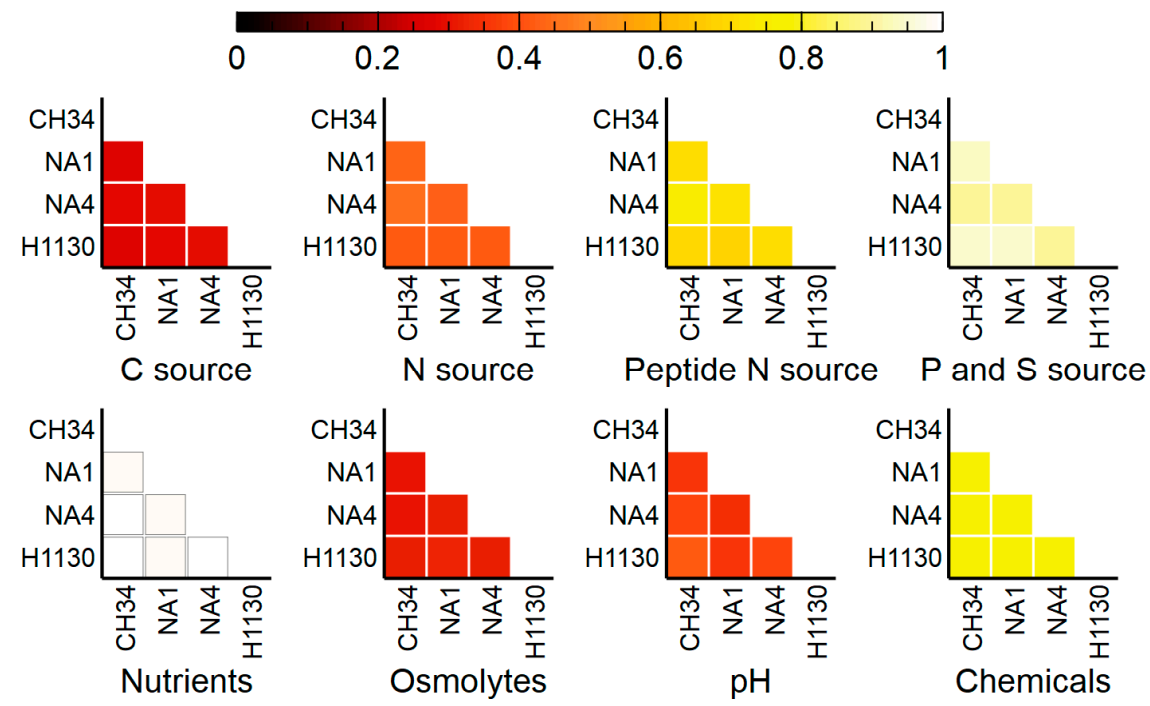

Figure 11. Overview of positive (growth) OmniLog phenotypic assays shared by C. metallidurans CH34, NA1, NA4 and H1130 for different metabolic and chemical sensitivity tests (with 1 being all assays shared).

\subsubsection{C, N, P and S Sources}

Only around $27 \%$ to $28 \%$ of the $C$ source reactions was positive, which is related to their inability to assimilate sugars and sugar alcohols (Figure 11) [1,3]. All four strains lack a glucose uptake system. The latter is most likely deleted in all four strains as a N-acetylglucosamine-specific phosphotransferase system (PTS)-type transport system essential for glucose uptake (growth) in Cupriavidus necator H16 [81,82] is absent in from a large syntenic region (>110 genes) conserved among C. necator H16 and C. metallidurans $\mathrm{CH} 34, \mathrm{NA} 1, \mathrm{NA} 4$ and $\mathrm{H} 1130$ (data not shown).

A few marked differences were observed for the use of amino acids as $\mathrm{N}$ source, in particular for L-leucine, L-tryptophan and L-Valine (Figure 12). Specific for L-tryptophan, growth was observed for NA1, NA4 and H1130 but not for CH34. Aerobic L-tryptophan degradation in C. metallidurans most likely occurs via a three-step pathway to anthrilanate requiring tryptophan 2,3-dioxygenase $(k y n A)$, kynurenine formamidase $(\mathrm{kyn} B)$ and kynureninase $(\mathrm{kyn} U)$. Experimental verification of the anthranilate pathway was achieved by functional expression of the CH34 kynBAU operon in Escherichia coli after suppressing the stop codon disrupting $k y n B$ [83]. This amber mutation is not present in NA1, NA4 and H1130, which could explain the observed differences. Similar differences were also observed when growth was scored for dipeptides (N source), as CH34 grew less or not on L-tryptophan-containing dipeptides compared to NA1, NA4 and H1130. Only minor differences were observed for growth on P and S sources (Figure 11, Table S4). 

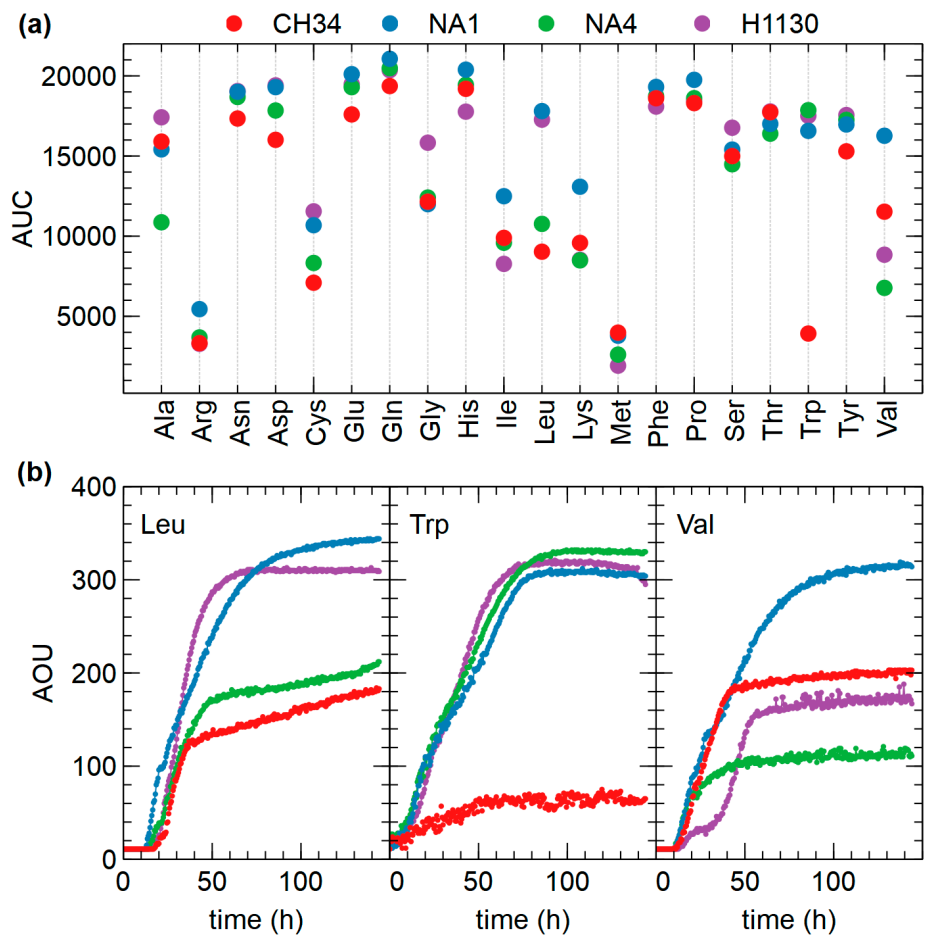

Figure 12. (a) Overview of OmniLog phenotypic assays with amino acids as $\mathrm{N}$ source (AUC = area under the curve) for C. metallidurans CH34, NA1, NA4 and H1130, (b) Growth kinetics in the presence of L-leucine, L-tryptophan and L-Valine as N source (AOU = arbitrary OmniLog units).

\subsubsection{Osmolytes and $\mathrm{pH}$}

The addition of ionic osmolytes had a clear and comparable impact on the growth of strains $\mathrm{CH} 34$, NA1, NA4 and H1130, as growth was generally only observed for the lower/lowest concentrations $\left(1 \% \mathrm{NaCl}, 2 \% \mathrm{Na}_{2} \mathrm{SO}_{4}, 1 \%\right.$ sodium formate, $3 \%$ urea and $2 \%$ sodium lactate). In contrast, addition of up to $20 \%$ of the non-ionic osmolyte ethylene glycol had no impact on growth of CH34, NA1, NA4 and $\mathrm{H} 1130$.

The effect of $\mathrm{pH}$ over the range 3.5 to 10 growth was comparable for CH34, NA1, NA4 and H1130. Growth was inhibited below $\mathrm{pH} 5$ for all strains. Growth at $\mathrm{pH} 10$ was much more pronounced for H1130 than for the other strains (Figure 13).
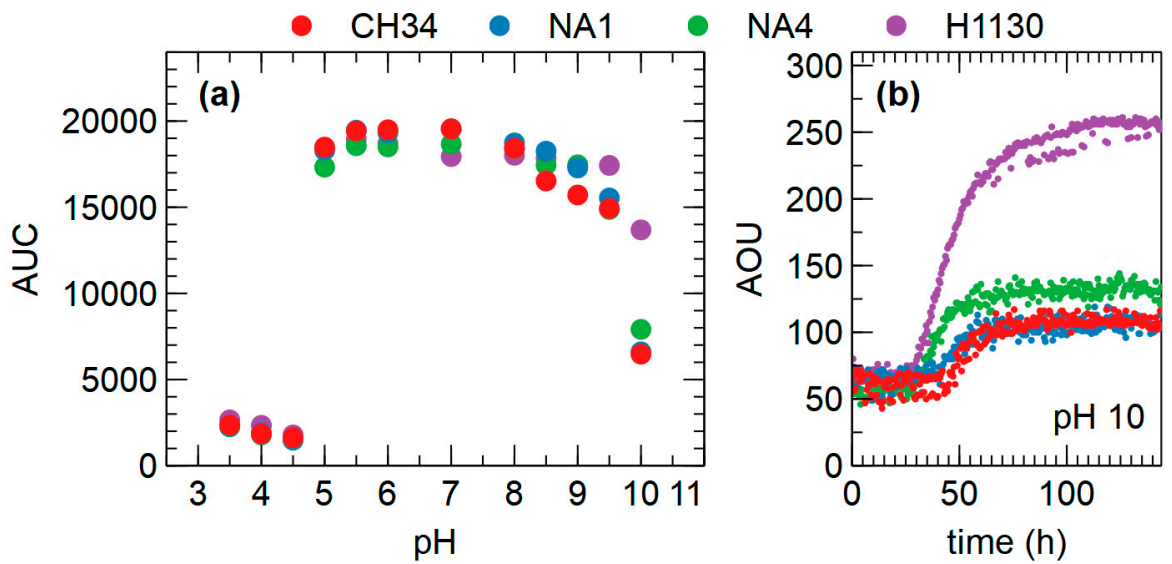

Figure 13. (a) Overview of OmniLog phenotypic assays related to $\mathrm{pH}$ (AUC = area under the curve) for C. metallidurans CH34, NA1, NA4 and H1130, (b) Growth kinetics at pH 10 (AOU = arbitrary OmniLog units). 


\subsubsection{Chemicals}

The PM-11 to PM-20 plates carry different chemicals (4 increasing concentrations of each) to test sensitivity, only for eight out of the 240 chemicals tested at least one of the strains was susceptible to the lowest concentration. For more than $50 \%$ of the tested chemicals, CH34, NA1, NA4 and H1130 were resistant to the highest concentration included in the phenotypic microarrays (Figure 14).

No growth was observed in the presence of 2,2'-dipyridyl (metal chelator), hydroxyurea (ROS producer) and phenethicillin (a narrow-spectrum, $\beta$-lactamase-sensitive penicillin) for all four strains. In contrast to phenethicillin, CH34, NA1, NA4 and H1130 were resistant to (at least one concentration of) all other $\beta$-lactam antibiotics tested. Only H1130 grew in the presence of sodium meta- and orthovanadate, and did not grow in the presence of thallium acetate (Figure 15). Strain CH34 and NA4 did not grow in the presence of potassium tellurite (Figure 15). The genetic basis underlying resistance to these metals is poorly understood, therefore, no correlation to the genotype could be established. Strain $\mathrm{CH} 34$ and NA1 were susceptible to sodium metaperiodate (oxidizing agent) and tolylfluanid (fungicide), respectively (Figure 15).

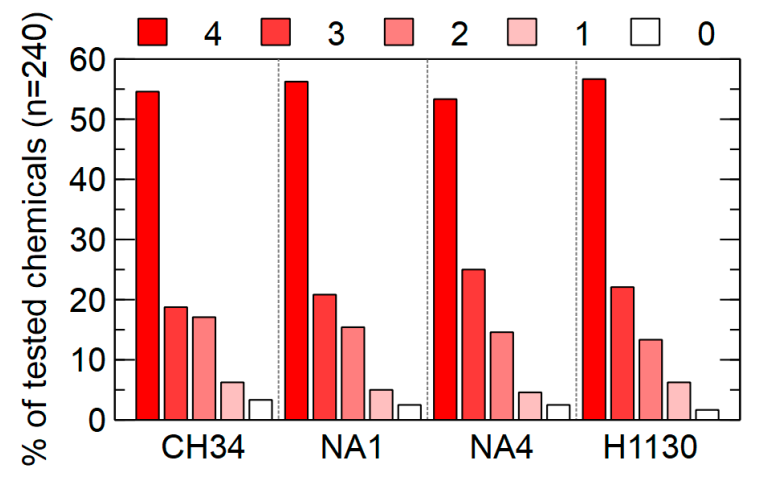

Figure 14. Percentage of tested chemicals $(n=240)$ to which C. metallidurans CH34, NA1, NA4 and H1130 are resistant. Four increasing concentrations are included in the phenotypic microarrays (0: susceptible to the lowest concentration, 1 to 4 : resistant to the lowest up to the highest concentration).

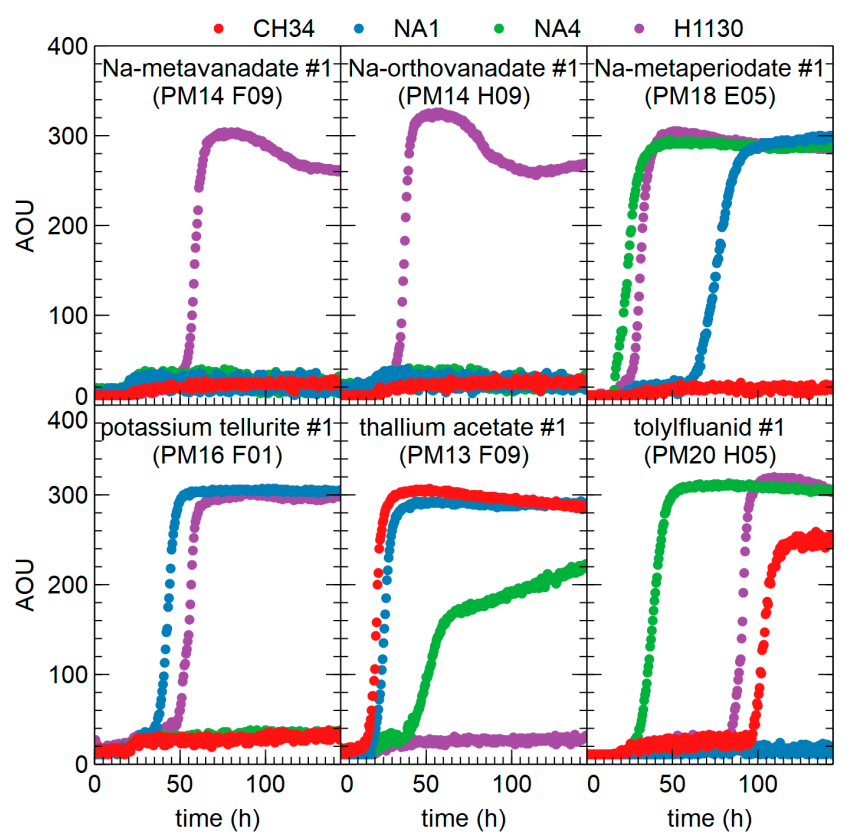

Figure 15. Growth kinetic of C. metallidurans CH34, NA1, NA4 and H1130 in the presence of different chemicals (lowest concentration in the phenotypic microarrays is shown) (AOU = arbitrary OmniLog units). 


\subsubsection{Trait Prediction}

Finally, the prediction of Traitar, an automated software framework for the accurate prediction of 67 phenotypes directly from a genome sequence [84], was evaluated by comparison with the generated phenotypic data (OmniLog Phenotypic Microarray data and previous observations/knowledge). Traitar correctly predicted $85 \%$ ( 45 out of 53 analyzed), $81 \%$ (38 out of 47 ), $80 \%$ (37 out of 46 ) and $80 \%$ (37 out of 46) of the $\mathrm{CH} 34$, NA1, NA4 and H1130 traits, respectively (Figure 16). Although Weimann and colleagues [84] indicated that the phypat classifier assigned more phenotypes at the price of more false-positive predictions, whereas the phypat + PGL classifier assigned fewer phenotypes with fewer false assignments, it appeared that in the case of the C. metallidurans strains, phypat + PGL assigned more false-positive predictions.

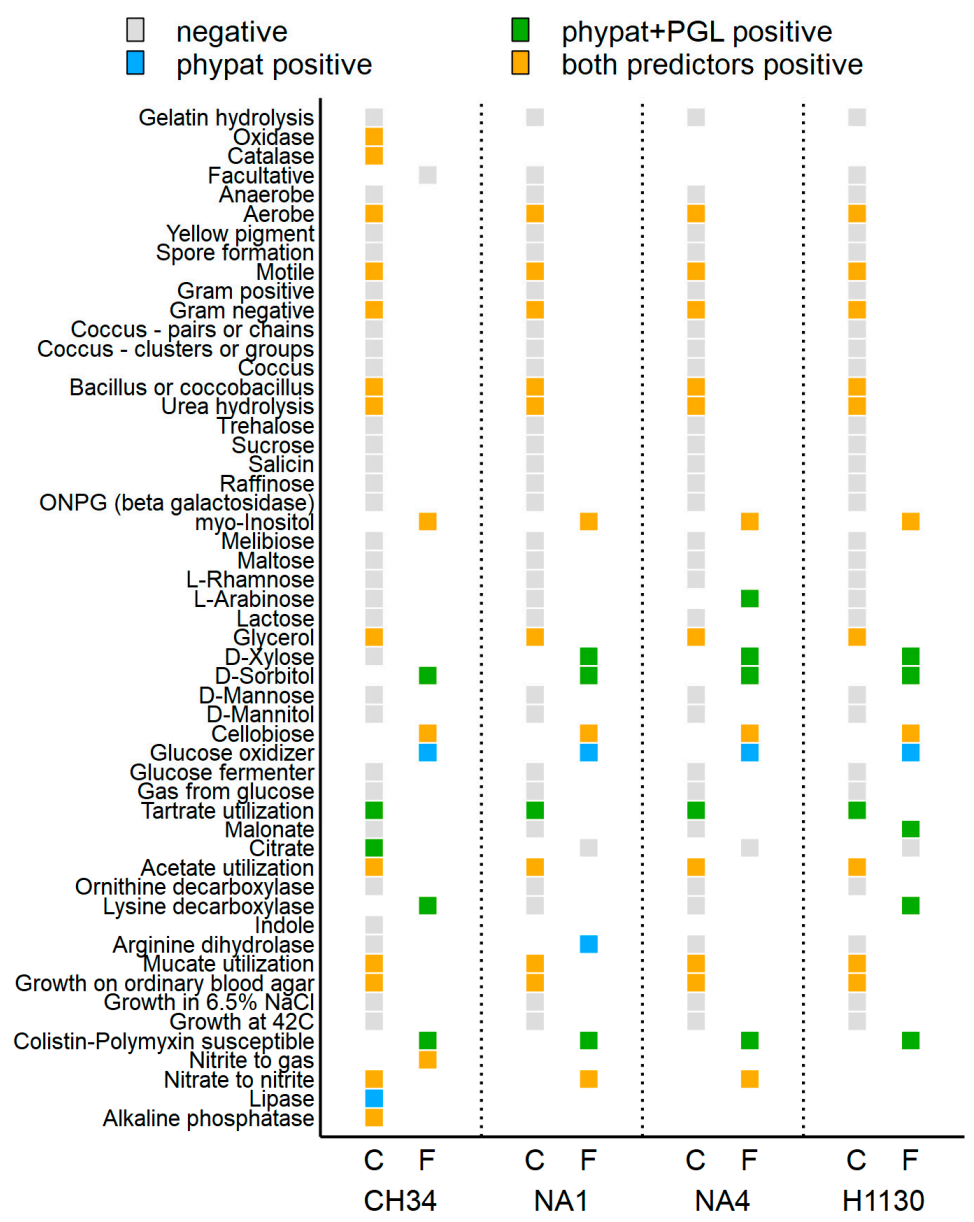

Figure 16. Overview of the correctly $(\mathrm{C})$ and falsely $(\mathrm{F})$ predicted phenotypic traits of $C$. metallidurans CH34, NA1, NA4 and H1130 by Traitar (two classifiers: phypat and phypat + PGL).

\section{Conclusions}

The comparison of four C. metallidurans strains isolated from different environments indicated that metal resistance determinants and properties are maintained in these environments. As most of the metal determinants are on the native megaplasmids, it could be argued that these environments provided a selective pressure for the conservation of these determinants and plasmids. The previously identified differences in the size and diversity of the mobile gene pool were put in perspective by the identification of intact (and remnant) prophages in NA4 and H1130, and a genomic island putatively involved in abietane diterpenoids metabolism in H1130. The latter indicated that mobilome diversity differed (integrative and conjugative elements/genomic islands versus prophages). Furthermore, the mobilome is apparently not directly related to the isolation environment as the NA1 mobilome is 
shaped more like that of H1130 than that of NA4 isolated from the same environment. In addition, an active CRISPR-Cas system was identified in strain NA4, providing immunity to a plasmid that integrated in $\mathrm{CH} 34$ and NA1. Despite the large size of the variable and specific genomes, only minor differences were observed in the global phenomes (as measured by phenotype microarrays) and all four strains were highly resistant to a wide variety of chemicals, much broader than metals. The variable and specific genome were probably acquired through later transfer and perhaps carry functions more essential for survival in challenging and fluctuating environments than general metabolic functions.

Supplementary Materials: The following are available online at http:/ /www.mdpi.com/2073-4425/9/10/507/s1, Figure S1: Density plot of the AUC values of all PM reactions for each strain, Figure S2: Progressive Mauve alignment of CMGI-1 of CH34 with related elements in NA1, NA4 and H1130, Table S1: Metal concentrations used in growth experiments, Table S2: Primers used in this study, Table S3: Pan-genome analysis data set, Table S4: PM area under the curve (AUC) values.

Author Contributions: Conceptualization, R.V.H.; Data curation, R.V.H. and P.M.; Formal analysis, R.V.H. and P.M.; Funding acquisition, R.V.H. and N.L.; Investigation, R.V.H., A.P., A.V.A. and K.M.; Methodology, R.V.H. and P.M.; Project administration, R.V.H.; Software, R.V.H. and P.M.; Supervision, R.V.H., N.L. and B.L.; Validation, R.V.H. and P.M.; Visualization, R.V.H.; Writing-original draft, R.V.H.; Writing—review \& editing, R.V.H., A.V.A., K.M. and P.M.

Funding: This work was funded by the European Space Agency (ESA-PRODEX) and the Belgian Science Policy (Belspo) through the COMICS project (C90356).

Conflicts of Interest: The authors declare no conflict of interest.

\section{References}

1. Mergeay, M.; Nies, D.; Schlegel, H.G.; Gerits, J.; Charles, P.; Van Gijsegem, F. Alcaligenes eutrophus CH34 is a facultative chemolithotroph with plasmid-bound resistance to heavy metals. J. Bacteriol. 1985, 162, 328-334. [PubMed]

2. Mergeay, M.; Van Houdt, R. Metal Response in Cupriavidus Metallidurans, Volume I: From Habitats to Genes and Proteins; Springer International Publishing: Cham, Switzerland, 2015; p. 89.

3. Janssen, P.J.; Van Houdt, R.; Moors, H.; Monsieurs, P.; Morin, N.; Michaux, A.; Benotmane, M.A.; Leys, N.; Vallaeys, T.; Lapidus, A.; et al. The complete genome sequence of Cupriavidus metallidurans strain $\mathrm{CH} 34$, a master survivalist in harsh and anthropogenic environments. PLoS ONE 2010, 5, e10433. [CrossRef] [PubMed]

4. Monchy, S.; Benotmane, M.A.; Janssen, P.; Vallaeys, T.; Taghavi, S.; van der Lelie, D.; Mergeay, M. Plasmids pMOL28 and pMOL30 of Cupriavidus metallidurans are specialized in the maximal viable response to heavy metals. J. Bacteriol. 2007, 189, 7417-7425. [CrossRef] [PubMed]

5. Vandenbussche, G.; Mergeay, M.; Van Houdt, R. Metal Response in Cupriavidus metallidurans, Volume II: Insights into the Structure-Function Relationship of Proteins; Springer International Publishing: Cham, Switzerland, 2015; p. 70.

6. Diels, L.; Mergeay, M. DNA probe-mediated detection of resistant bacteria from soils highly polluted by heavy metals. Appl. Environ. Microbiol. 1990, 56, 1485-1491. [PubMed]

7. Van Houdt, R.; Monsieurs, P.; Mijnendonckx, K.; Provoost, A.; Janssen, A.; Mergeay, M.; Leys, N. Variation in genomic islands contribute to genome plasticity in Cupriavidus metallidurans. BMC Genom. 2012, 13, 111. [CrossRef] [PubMed]

8. Kunito, T.; Kusano, T.; Oyaizu, H.; Senoo, K.; Kanazawa, S.; Matsumoto, S. Cloning and sequence analysis of czc genes in Alcaligenes sp. strain CT14. Biosci. Biotechnol. Biochem. 1996, 60, 699-704. [CrossRef] [PubMed]

9. Reith, F.; Rogers, S.L.; McPhail, D.C.; Webb, D. Biomineralization of gold: Biofilms on bacterioform gold. Science 2006, 313, 233-236. [CrossRef] [PubMed]

10. Schmidt, T.; Schlegel, H.G. Nickel and cobalt resistance of various bacteria isolated from soil and highly polluted domestic and industrial wastes. FEMS Microbiol. Lett. 1989, 62, 315-328. [CrossRef]

11. Miyake-Nakayama, C.; Masujima, S.; Ikatsu, H.; Miyoshi, S.-I.; Shinoda, S. Isolation and characterization of a new dichloromethane degrading bacterium, Ralstonia metallidurans, PD11. Biocontrol Sci. 2004, 9, 89-93. [CrossRef] 
12. Mijnendonckx, K.; Provoost, A.; Ott, C.M.; Venkateswaran, K.; Mahillon, J.; Leys, N.; Van Houdt, R. Characterization of the survival ability of Cupriavidus metallidurans and Ralstonia pickettii from space-related environments. Microbol. Ecol. 2013, 65, 347-360. [CrossRef] [PubMed]

13. Mora, M.; Perras, A.; Alekhova, T.A.; Wink, L.; Krause, R.; Aleksandrova, A.; Novozhilova, T.; Moissl-Eichinger, C. Resilient microorganisms in dust samples of the International Space Station-survival of the adaptation specialists. Microbiome 2016, 4, 65. [CrossRef] [PubMed]

14. Coenye, T.; Spilker, T.; Reik, R.; Vandamme, P.; Lipuma, J.J. Use of PCR analyses to define the distribution of Ralstonia species recovered from patients with cystic fibrosis. J. Clin. Microbiol. 2005, 43, 3463-3466. [CrossRef] [PubMed]

15. Langevin, S.; Vincelette, J.; Bekal, S.; Gaudreau, C. First case of invasive human infection caused by Cupriavidus metallidurans. J. Clin. Microbiol. 2011, 49, 744-745. [CrossRef] [PubMed]

16. D'Inzeo, T.; Santangelo, R.; Fiori, B.; De Angelis, G.; Conte, V.; Giaquinto, A.; Palucci, I.; Scoppettuolo, G.; Di Florio, V.; Giani, T.; et al. Catheter-related bacteremia by Cupriavidus metallidurans. Diagn. Microbiol. Infect. Dis. 2015, 81, 9-12. [CrossRef] [PubMed]

17. Harrison, P.W.; Lower, R.P.; Kim, N.K.; Young, J.P. Introducing the bacterial 'chromid': Not a chromosome, not a plasmid. Trends Microbiol. 2010, 18, 141-148. [CrossRef] [PubMed]

18. DiCenzo, G.C.; Finan, T.M. The divided bacterial genome: Structure, function, and evolution. Microbiol. Mol. Biol. Rev. 2017, 81, e00019-17. [CrossRef] [PubMed]

19. Schwartz, E. Microbial Megaplasmids; Springer: Berlin/Heidelberg, Germany, 2009; p. 348.

20. Schwartz, E.; Henne, A.; Cramm, R.; Eitinger, T.; Friedrich, B.; Gottschalk, G. Complete nucleotide sequence of pHG1: A Ralstonia eutropha $\mathrm{H} 16$ megaplasmid encoding key enzymes of $\mathrm{H}_{2}$-based lithoautotrophy and anaerobiosis. J. Mol. Biol. 2003, 332, 369-383. [CrossRef]

21. Amadou, C.; Pascal, G.; Mangenot, S.; Glew, M.; Bontemps, C.; Capela, D.; Carrere, S.; Cruveiller, S.; Dossat, C.; Lajus, A.; et al. Genome sequence of the $\beta$-rhizobium Cupriavidus taiwanensis and comparative genomics of rhizobia. Genom. Res. 2008, 18, 1472-1483. [CrossRef] [PubMed]

22. Trefault, N.; De la Iglesia, R.; Molina, A.M.; Manzano, M.; Ledger, T.; Perez-Pantoja, D.; Sanchez, M.A.; Stuardo, M.; Gonzalez, B. Genetic organization of the catabolic plasmid pJP4 from Ralstonia eutropha JMP134 (pJP4) reveals mechanisms of adaptation to chloroaromatic pollutants and evolution of specialized chloroaromatic degradation pathways. Environ. Microbiol. 2004, 6, 655-668. [CrossRef] [PubMed]

23. Van Houdt, R.; Mergeay, M. Genomic context of metal response genes in Cupriavidus metallidurans with a focus on strain CH34. In Metal Response in Cupriavidus Metallidurans, Volume I: From Habitats to Genes and Proteins; Mergeay, M., Van Houdt, R., Eds.; Springer International Publishing: Cham, Switzerland, 2015; pp. 21-44.

24. Mijnendonckx, K.; Provoost, A.; Monsieurs, P.; Leys, N.; Mergeay, M.; Mahillon, J.; Van Houdt, R. Insertion sequence elements in Cupriavidus metallidurans CH34: Distribution and role in adaptation. Plasmid 2011, 65, 193-203. [CrossRef] [PubMed]

25. Van Houdt, R.; Monchy, S.; Leys, N.; Mergeay, M. New mobile genetic elements in Cupriavidus metallidurans $\mathrm{CH} 34$, their possible roles and occurrence in other bacteria. Antonie Leeuwenhoek 2009, 96, 205-226. [CrossRef] [PubMed]

26. Juhas, M.; van der Meer, J.R.; Gaillard, M.; Harding, R.M.; Hood, D.W.; Crook, D.W. Genomic islands: Tools of bacterial horizontal gene transfer and evolution. FEMS Microbiol. Rev. 2009, 33, 376-393. [CrossRef] [PubMed]

27. Vandecraen, J.; Chandler, M.; Aertsen, A.; Van Houdt, R. The impact of insertion sequences on bacterial genome plasticity and adaptability. Crit. Rev. Microbiol. 2017, 43, 709-730. [CrossRef] [PubMed]

28. Obeng, N.; Pratama, A.A.; Elsas, J.D.V. The significance of mutualistic phages for bacterial ecology and evolution. Trends Microbiol. 2016, 24, 440-449. [CrossRef] [PubMed]

29. Bondy-Denomy, J.; Davidson, A.R. When a virus is not a parasite: The beneficial effects of prophages on bacterial fitness. J. Microbiol. 2014, 52, 235-242. [CrossRef] [PubMed]

30. Bochner, B.R.; Gadzinski, P.; Panomitros, E. Phenotype microarrays for high-throughput phenotypic testing and assay of gene function. Genom. Res. 2001, 11, 1246-1255. [CrossRef] [PubMed]

31. Mergeay, M.; Houba, C.; Gerits, J. Extrachromosomal inheritance controlling resistance to cadmium, cobalt, copper and zinc ions: Evidence from curing a Pseudomonas. Arch. Int. Physiol. Biochim. Biophys. 1978, 86, $440-442$. 
32. Ferrieres, L.; Hemery, G.; Nham, T.; Guerout, A.M.; Mazel, D.; Beloin, C.; Ghigo, J.M. Silent mischief: Bacteriophage $\mathrm{Mu}$ insertions contaminate products of Escherichia coli random mutagenesis performed using suicidal transposon delivery plasmids mobilized by broad-host-range RP4 conjugative machinery. J. Bacteriol. 2010, 192, 6418-6427. [CrossRef] [PubMed]

33. Schafer, A.; Tauch, A.; Jager, W.; Kalinowski, J.; Thierbach, G.; Puhler, A. Small mobilizable multi-purpose cloning vectors derived from the Escherichia coli plasmids pK18 and pK19: Selection of defined deletions in the chromosome of Corynebacterium glutamicum. Gene 1994, 145, 69-73. [CrossRef]

34. Chang, A.C.; Cohen, S.N. Construction and characterization of amplifiable multicopy DNA cloning vehicles derived from the p15A cryptic miniplasmid. J. Bacteriol. 1978, 134, 1141-1156. [PubMed]

35. Blatny, J.M.; Brautaset, T.; Winther-Larsen, H.C.; Haugan, K.; Valla, S. Construction and use of a versatile set of broad-host-range cloning and expression vectors based on the RK2 replicon. Appl. Environ. Microbiol. 1997, 63, 370-379. [PubMed]

36. Andrup, L.; Barfod, K.K.; Jensen, G.B.; Smidt, L. Detection of large plasmids from the Bacillus cereus group. Plasmid 2008, 59, 139-143. [CrossRef] [PubMed]

37. Vaas, L.A.; Sikorski, J.; Hofner, B.; Fiebig, A.; Buddruhs, N.; Klenk, H.P.; Goker, M. opm: An R package for analysing OmniLog ${ }^{\circledR}$ phenotype microarray data. Bioinformatics 2013, 29, 1823-1824. [CrossRef] [PubMed]

38. Vaas, L.A.; Sikorski, J.; Michael, V.; Goker, M.; Klenk, H.P. Visualization and curve-parameter estimation strategies for efficient exploration of phenotype microarray kinetics. PLoS ONE 2012, 7, e34846. [CrossRef] [PubMed]

39. Vallenet, D.; Belda, E.; Calteau, A.; Cruveiller, S.; Engelen, S.; Lajus, A.; Le Fevre, F.; Longin, C.; Mornico, D.; Roche, D.; et al. MicroScope-An integrated microbial resource for the curation and comparative analysis of genomic and metabolic data. Nucleic Acids Res. 2013, 41, D636-647. [CrossRef] [PubMed]

40. Miele, V.; Penel, S.; Duret, L. Ultra-fast sequence clustering from similarity networks with SiLiX. BMC Bioinf. 2011, 12, 116. [CrossRef] [PubMed]

41. Ondov, B.D.; Treangen, T.J.; Melsted, P.; Mallonee, A.B.; Bergman, N.H.; Koren, S.; Phillippy, A.M. Mash: Fast genome and metagenome distance estimation using MinHash. Genom. Biol. 2016, 17, 132. [CrossRef] [PubMed]

42. McArthur, A.G.; Waglechner, N.; Nizam, F.; Yan, A.; Azad, M.A.; Baylay, A.J.; Bhullar, K.; Canova, M.J.; De Pascale, G.; Ejim, L.; et al. The comprehensive antibiotic resistance database. Antimicrob. Agents Chemother. 2013, 57, 3348-3357. [CrossRef] [PubMed]

43. McArthur, A.G.; Wright, G.D. Bioinformatics of antimicrobial resistance in the age of molecular epidemiology. Curr. Opin. Microbiol. 2015, 27, 45-50. [CrossRef] [PubMed]

44. Jia, B.; Raphenya, A.R.; Alcock, B.; Waglechner, N.; Guo, P.; Tsang, K.K.; Lago, B.A.; Dave, B.M.; Pereira, S.; Sharma, A.N.; et al. CARD 2017: Expansion and model-centric curation of the comprehensive antibiotic resistance database. Nucleic Acids Res. 2017, 45, D566-D573. [CrossRef] [PubMed]

45. Pal, C.; Bengtsson-Palme, J.; Rensing, C.; Kristiansson, E.; Larsson, D.G. BacMet: Antibacterial biocide and metal resistance genes database. Nucleic Acids Res. 2014, 42, D737-D743. [CrossRef] [PubMed]

46. Monsieurs, P.; Provoost, A.; Mijnendonckx, K.; Leys, N.; Gaudreau, C.; Van Houdt, R. Genome sequence of Cupriavidus metallidurans Strain H1130, isolated from an invasive human infection. Genom. Announc. 2013, 1, e01051-13. [CrossRef] [PubMed]

47. Monsieurs, P.; Mijnendonckx, K.; Provoost, A.; Venkateswaran, K.; Ott, C.M.; Leys, N.; Van Houdt, R. Genome sequences of Cupriavidus metallidurans strains NA1, NA4, and NE12, isolated from space equipment. Genom. Announc. 2014, 2, e00719-14. [CrossRef] [PubMed]

48. Tatusov, R.L.; Galperin, M.Y.; Natale, D.A.; Koonin, E.V. The COG database: A tool for genome-scale analysis of protein functions and evolution. Nucleic Acids Res. 2000, 28, 33-36. [CrossRef] [PubMed]

49. Siguier, P.; Perochon, J.; Lestrade, L.; Mahillon, J.; Chandler, M. ISfinder: The reference centre for bacterial insertion sequences. Nucleic Acids Res. 2006, 34, D32-D36. [CrossRef] [PubMed]

50. Varani, A.M.; Siguier, P.; Gourbeyre, E.; Charneau, V.; Chandler, M. ISsaga is an ensemble of web-based methods for high throughput identification and semi-automatic annotation of insertion sequences in prokaryotic genomes. Genom. Biol. 2011, 12, R30. [CrossRef] [PubMed]

51. Ricker, N.; Qian, H.; Fulthorpe, R.R. The limitations of draft assemblies for understanding prokaryotic adaptation and evolution. Genomics 2012, 100, 167-175. [CrossRef] [PubMed] 
52. Dong, Q.; Sadouk, A.; van der Lelie, D.; Taghavi, S.; Ferhat, A.; Nuyten, J.M.; Borremans, B.; Mergeay, M.; Toussaint, A. Cloning and sequencing of IS1086, an Alcaligenes eutrophus insertion element related to IS30 and IS4351. J. Bacteriol. 1992, 174, 8133-8138. [CrossRef] [PubMed]

53. Collard, J.M.; Provoost, A.; Taghavi, S.; Mergeay, M. A new type of Alcaligenes eutrophus CH34 zinc resistance generated by mutations affecting regulation of the cnr cobalt-nickel resistance system. J. Bacteriol. 1993, 175, 779-784. [CrossRef] [PubMed]

54. Grass, G.; Grosse, C.; Nies, D.H. Regulation of the cnr cobalt and nickel resistance determinant from Ralstonia sp. strain CH34. J. Bacteriol. 2000, 182, 1390-1398. [CrossRef] [PubMed]

55. Talat, M.-E. Genetic Mechanism of Heavy Metal Resistance of Pseudomonas aeruginosa CMG103. Ph.D. Thesis, University of Karachi, Karachi, Pakistan, 2000.

56. Schneider, D.; Faure, D.; Noirclerc-Savoye, M.; Barriere, A.C.; Coursange, E.; Blot, M. A broad-host-range plasmid for isolating mobile genetic elements in gram-negative bacteria. Plasmid 2000, 44, 201-207. [CrossRef] [PubMed]

57. Tibazarwa, C.; Wuertz, S.; Mergeay, M.; Wyns, L.; van der Lelie, D. Regulation of the cnr cobalt and nickel resistance determinant of Ralstonia eutropha (Alcaligenes eutrophus) CH34. J. Bacteriol. 2000, 182, 1399-1409. [CrossRef] [PubMed]

58. Vandecraen, J.; Monsieurs, P.; Mergeay, M.; Leys, N.; Aertsen, A.; Van Houdt, R. Zinc-induced transposition of insertion sequence elements contributes to increased adaptability of Cupriavidus metallidurans. Front. Microbiol. 2016, 7, 359. [CrossRef] [PubMed]

59. Providenti, M.A.; Shaye, R.E.; Lynes, K.D.; McKenna, N.T.; O’Brien, J.M.; Rosolen, S.; Wyndham, R.C.; Lambert, I.B. The locus coding for the 3-nitrobenzoate dioxygenase of Comamonas sp. strain JS46 is flanked by IS1071 elements and is subject to deletion and inversion events. Appl. Environ. Microbiol. 2006, 72, 2651-2660. [CrossRef] [PubMed]

60. Clement, P.; Pieper, D.H.; Gonzalez, B. Molecular characterization of a deletion/duplication rearrangement in $t f d$ genes from Ralstonia eutropha JMP134(pJP4) that improves growth on 3-chlorobenzoic acid but abolishes growth on 2,4-dichlorophenoxyacetic acid. Microbiology 2001, 147, 2141-2148. [CrossRef] [PubMed]

61. Mindlin, S.; Petrova, M. Mercury resistance transposons. In Bacterial Integrative Mobile Genetic Elements; Roberts, A.P., Mullany, P., Eds.; Landes Biosciences: Austin, TX, USA, 2013; pp. 33-52.

62. Miyazaki, R.; Minoia, M.; Pradervand, N.; Sentchilo, V.; Sulser, S.; Reinhard, F.; van der Meer, J.R. The clc Element and Related Genomic Islands in Proteobacteria. In Bacterial Integrative Mobile Genetic Elements; Roberts, A.P., Mullany, P., Eds.; Landes Bioscience: Austin, TX, USA, 2013; pp. 261-272.

63. Klockgether, J.; Wurdemann, D.; Reva, O.; Wiehlmann, L.; Tummler, B. Diversity of the abundant pKLC102/PAGI-2 family of genomic islands in Pseudomonas aeruginosa. J. Bacteriol. 2007, 189, 2443-2459. [CrossRef] [PubMed]

64. Darling, A.E.; Mau, B.; Perna, N.T. progressiveMauve: Multiple genome alignment with gene gain, loss and rearrangement. PLoS ONE 2010, 5, e11147. [CrossRef] [PubMed]

65. Van Houdt, R.; Toussaint, A.; Ryan, M.P.; Pembroke, J.T.; Mergeay, M.; Adley, C.C. The Tn4371 ICE Family of Bacterial Mobile Genetic Elements. In Bacterial Integrative Mobile Genetic Elements; Roberts, A.P., Mullany, P., Eds.; Landes Bioscience: Austin, TX, USA, 2013; pp. 179-200.

66. Smith, D.J.; Park, J.; Tiedje, J.M.; Mohn, W.W. A large gene cluster in Burkholderia xenovorans encoding abietane diterpenoid catabolism. J. Bacteriol. 2007, 189, 6195-6204. [CrossRef] [PubMed]

67. Byun-McKay, A.; Godard, K.A.; Toudefallah, M.; Martin, D.M.; Alfaro, R.; King, J.; Bohlmann, J.; Plant, A.L. Wound-induced terpene synthase gene expression in Sitka spruce that exhibit resistance or susceptibility to attack by the white pine weevil. Plant Physiol. 2006, 140, 1009-1021. [CrossRef] [PubMed]

68. Arndt, D.; Grant, J.R.; Marcu, A.; Sajed, T.; Pon, A.; Liang, Y.; Wishart, D.S. PHASTER: A better, faster version of the PHAST phage search tool. Nucleic Acids Res. 2016, 44, W16-W21. [CrossRef] [PubMed]

69. Sorek, R.; Lawrence, C.M.; Wiedenheft, B. CRISPR-mediated adaptive immune systems in bacteria and archaea. Annu. Rev. Biochem. 2013, 82, 237-266. [CrossRef] [PubMed]

70. Grissa, I.; Vergnaud, G.; Pourcel, C. CRISPRFinder: A web tool to identify clustered regularly interspaced short palindromic repeats. Nucleic Acids Res. 2007, 35, W52-W57. [CrossRef] [PubMed]

71. Biswas, A.; Staals, R.H.; Morales, S.E.; Fineran, P.C.; Brown, C.M. CRISPRDetect: A flexible algorithm to define CRISPR arrays. BMC Genom. 2016, 17, 356. [CrossRef] [PubMed] 
72. Biswas, A.; Fineran, P.C.; Brown, C.M. Computational Detection of CRISPR/crRNA Targets. Methods Mol. Biol. 2015, 1311, 77-89. [PubMed]

73. Monsieurs, P.; Moors, H.; Van Houdt, R.; Janssen, P.J.; Janssen, A.; Coninx, I.; Mergeay, M.; Leys, N. Heavy metal resistance in Cupriavidus metallidurans $\mathrm{CH} 34$ is governed by an intricate transcriptional network. BioMetals 2011, 24, 1133-1151. [CrossRef] [PubMed]

74. Henne, K.L.; Nakatsu, C.H.; Thompson, D.K.; Konopka, A.E. High-level chromate resistance in Arthrobacter sp. strain FB24 requires previously uncharacterized accessory genes. BMC Microbiol. 2009, 9, 199. [CrossRef] [PubMed]

75. Henne, K.L.; Turse, J.E.; Nicora, C.D.; Lipton, M.S.; Tollaksen, S.L.; Lindberg, C.; Babnigg, G.; Giometti, C.S.; Nakatsu, C.H.; Thompson, D.K.; et al. Global proteomic analysis of the chromate response in Arthrobacter sp. strain FB24. J. Proteome Res. 2009, 8, 1704-1716. [CrossRef] [PubMed]

76. Nies, D.H.; Rehbein, G.; Hoffmann, T.; Baumann, C.; Grosse, C. Paralogs of genes encoding metal resistance proteins in Cupriavidus metallidurans strain CH34. J. Mol. Microbiol. Biotechnol. 2006, 11, 82-93. [CrossRef] [PubMed]

77. Hlozkova, K.; Suman, J.; Strnad, H.; Ruml, T.; Paces, V.; Kotrba, P. Characterization of pbt genes conferring increased $\mathrm{Pb}^{2+}$ and $\mathrm{Cd}^{2+}$ tolerance upon Achromobacter xylosoxidans A8. Res. Microbiol. 2013, 164, 1009-1018. [CrossRef] [PubMed]

78. Wiesemann, N.; Mohr, J.; Grosse, C.; Herzberg, M.; Hause, G.; Reith, F.; Nies, D.H. Influence of copper resistance determinants on gold transformation by Cupriavidus metallidurans strain CH34. J. Bacteriol. 2013, 195, 2298-2308. [CrossRef] [PubMed]

79. Reith, F.; Etschmann, B.; Grosse, C.; Moors, H.; Benotmane, M.A.; Monsieurs, P.; Grass, G.; Doonan, C.; Vogt, S.; Lai, B.; et al. Mechanisms of gold biomineralization in the bacterium Cupriavidus metallidurans. Proc. Natl. Acad. Sci. USA 2009, 106, 17757-17762. [CrossRef] [PubMed]

80. Schmidt, T.; Schlegel, H.G. Combined nickel-cobalt-cadmium resistance encoded by the ncc locus of Alcaligenes xylosoxidans 31A. J. Bacteriol. 1994, 176, 7045-7054. [CrossRef] [PubMed]

81. Orita, I.; Iwazawa, R.; Nakamura, S.; Fukui, T. Identification of mutation points in Cupriavidus necator NCIMB 11599 and genetic reconstitution of glucose-utilization ability in wild strain H16 for polyhydroxyalkanoate production. J. Biosci. Bioeng. 2012, 113, 63-69. [CrossRef] [PubMed]

82. Raberg, M.; Peplinski, K.; Heiss, S.; Ehrenreich, A.; Voigt, B.; Doring, C.; Bomeke, M.; Hecker, M.; Steinbuchel, A. Proteomic and transcriptomic elucidation of the mutant Ralstonia eutropha $\mathrm{G}+1$ with regard to glucose utilization. Appl. Environ. Microbiol. 2011, 77, 2058-2070. [CrossRef] [PubMed]

83. Kurnasov, O.; Jablonski, L.; Polanuyer, B.; Dorrestein, P.; Begley, T.; Osterman, A. Aerobic tryptophan degradation pathway in bacteria: Novel kynurenine formamidase. FEMS Microbiol. Lett. 2003, 227, $219-227$. [CrossRef]

84. Weimann, A.; Mooren, K.; Frank, J.; Pope, P.B.; Bremges, A.; McHardy, A.C. From genomes to phenotypes: Traitar, the microbial trait analyzer. mSystems 2016, 1, e00101-16. [CrossRef] [PubMed] 